\title{
The Psychological Effect of Weather on Car Purchases
}

\author{
Meghan R. Busse \\ Devin G. Pope \\ Jaren C. Pope \\ Jorge Silva-Risso*
}

May 2014

\begin{abstract}
When buying durable goods, consumers must forecast how much utility they will derive from future consumption, including consumption in different states of the world. This can be complicated for consumers since making intertemporal evaluations may expose consumers to a variety of psychological biases such as present bias, projection bias, and salience effects. We investigate whether consumers are affected by such intertemporal biases when they purchase automobiles. Using data for more than forty million vehicle transactions, we explore the impact of weather on purchasing decisions. We find that the choice to purchase a convertible or a 4-wheel drive is highly dependent on the weather at the time of purchase in a way that is inconsistent with classical utility theory. We consider a range of rational explanations for the empirical effects we find, but none can explain fully the effects we estimate. We then discuss and explore projection bias and salience as two primary psychological mechanisms that are consistent with our results.
\end{abstract}

\footnotetext{
*Busse: Kellogg School of Management, Northwestern University and NBER; D. Pope: Booth School of Business, University of Chicago and NBER; J. Pope: Department of Economics, Brigham Young University; Silva-Risso: School of Business Administration, UC Riverside. We are grateful to Chris Bruegge and Ezra Karger for valuable research assistance. We also thank Stefano DellaVigna, Glenn Ellison, Emir Kamenica, Ulrike Malmendier, Ted O’Donoghue, Loren Pope, Joe Price, Mathew Rabin, Chad Syverson, Dick Thaler, and seminar participants at the Behavioral Economics Annual Meeting, the ISMS Marketing Science Conference, the NBER Summer Institute, the Psychonomic Society Annual Meeting, Brigham Young University, Columbia University, Cornell University, DePaul University, Harvard Business School, Indiana University, MIT, Simon Fraser University, Stanford University, UC Berkeley, UC Los Angeles, UC San Diego, UC Santa Barbara, University of British Columbia, University of Chicago, University of Illinois, University of Kentucky, University of Zurich, the Wharton School, and Yale University for helpful suggestions. We are also very grateful for helpful input from the editors and three anonymous referees.
} 


\section{Introduction}

People make many decisions that require them to evaluate not only current benefits and costs, but future utility as well. For example, choosing a job, deciding where to live, planning a vacation, deciding whether to have a baby, and purchasing a durable good are all important life decisions that require an individual to think about utility that will accrue in the future. The standard economic model assumes that individuals are able to accurately estimate future benefits and costs, and thereby make decisions that maximize intertemporal utility. Evidence from psychology, however, suggests that individuals may make systematic errors when making intertemporal decisions. Cautions against such systematic errors are contained in the familiar advice to "never shop on an empty stomach," to "sleep on it" before making an important decision, and to "decide what you are going to buy before walking in the store." Recent psychological models such as present-biased preferences (Laibson, 1997; O’Donoghue \& Rabin, 1999), projection bias (Loewenstein, O’Donoghue, and Rabin, 2003), salience (Bordalo, Gennaioli, and Shleifer, 2013), and others provide underlying mechanisms for why consumers make decisions that are too heavily influenced by their mental and/or emotional state at the time of the decision.

In this paper, we test whether consumers are overly influenced by conditions at the time of purchase in one particular high-stakes environment, the car market. Since vehicles are durable goods, consumers must predict at the time of purchase which vehicle will generate the highest intertemporal utility across the future states of the world. We posit that consumers may mistakenly purchase a vehicle that has a high perceived utility at the time of purchase, but whose realized utility is systematically lower. Specifically, we test the extent to which weather variation at the time of purchase can cause consumers to overweigh the value that they place on certain vehicle characteristics. We predict that consumers will overvalue warm-weather vehicle types (e.g. convertibles) when the weather is warm and sunny at the time of purchase and overvalue cold- 
weather vehicle types (e.g. 4-wheel-drive vehicles) when the weather is cold and snowy at the time of purchase. We choose to focus our attention on a large and long-lived durable good for two reasons. First, the weather on the day of purchase will have very little effect on the total intertemporal utility consumers will obtain from owning a vehicle. This means that a fully rational, utility maximizing consumer should respond very little to the current weather when buying a car (although he or she might very reasonably put great weight on the current weather when buying an ice cream cone or a cup of hot cocoa). Second, consumers-knowing that vehicles are very expensive and that they will likely keep the vehicle for several years—attempt to make the correct long-term decision. Thus, finding bias in this setting is particularly compelling evidence of the importance of psychological biases on individual decision making.

We explore this hypothesis using transaction-level data for more than forty million new and used vehicles from dealerships around the United States. We find that the sales of convertibles and 4-wheel drives are highly influenced by idiosyncratic variation in temperature, cloud cover, and snowfall. We show that for convertibles, weather that is warmer and skies that are clearer than seasonal averages lead to a higher fraction of cars being sold that are convertibles. Controlling for seasonal sales patterns, our estimates suggest that a location that experiences a temperature that is 10 degrees higher than normal will experience a $2.7 \%$ increase in the fraction of cars sold that are convertibles. We find large and significant effects both in the spring and in the fall (e.g. an atypically warm day in November increases the fraction of vehicles sold that are convertibles). Importantly, we also show that atypically warm weather does not impact fraction of cars sold that are convertibles when the temperature is already high (above 75 or 80 degrees Fahrenheit). Purchases of 4-wheel drive vehicles are also very responsive to idiosyncratic weather variation-particularly snowfall. Our results suggest that a snow storm of approximately 10 inches will increase the fraction of vehicles sold that have 4 -wheel drive by about $6 \%$ over the next $2-3$ weeks. 
In the paper we consider ways in which these effects could arise from consumers behaving as standard, rational economic agents. The data allow us to rule out that these standard rational-agent models can fully explain our findings. For example, a distributed lag model indicates that the increase in convertible and 4-wheel drive sales due to idiosyncratic weather variation cannot be explained by short-run substitutions in vehicle purchases across days (a "harvesting effect"). We also present evidence that learning about a vehicle during a test drive (which for a convertible may be easier to do on a warm day) is unlikely to explain the results we find. In particular, cloud cover (which does not limit the ability to test drive a vehicle as temperature might) has a large impact on sales. Furthermore, individuals who previously owned a convertible and thus have less to learn about their value for convertible attributes are also affected by idiosyncratic weather conditions.

We next consider psychological mechanisms that might explain our empirical findings. We show that our results are consistent with both projection bias and salience, psychological effects that are closely related in this context.

Our findings are significant for several reasons. First, vehicles are one of the highest value purchases that most households make. Identifying, and potentially correcting, systematic errors in this market can have important welfare implications. Perhaps more importantly, our results suggest that focusing too much on conditions at the time of decision may be a mistake that is prevalent in other contexts (getting married, buying a house, choosing a job, etc.) that are similarly distinguished by having large stakes, state-dependent utility, and low-frequency decision making.

Our paper is related to a growing literature that uses field data to test models from behavioral economics (see DellaVigna (2009) for a review). Our paper is most similar to the work of Conlin, O’Donoghue, and Vogelsang (2007) who test for intertemporal bias in catalog order purchases. They convincingly show that decisions to purchase cold-weather items are overinfluenced by the weather at the time of purchase. Specifically, they find that if the temperature at the time of a 
purchase is 30 degrees lower, consumers are 0.57 percentage points more likely to return a purchased item (a 3.95\% increase relative to the average return rate). They argue that these empirical findings fit the predictions made by a model of projection bias. Our paper complements this earlier work.

The paper proceeds as follows. In section 2, we describe the vehicle market and weather data we use in the paper. In section 3, we estimate the effect of short-term weather fluctuations on vehicle purchasing. In section 4, we consider a variety of rational explanations for the weather effects we estimate in section 3, including the empirical evidence in support of each. In section 5, we discuss several psychological explanations for our estimated weather effects, and evaluate the empirical evidence for each. Section 6 concludes the paper.

\section{Data and Empirical Strategy}

The data used in our analysis contain information about automobile transactions from a sample of about $20 \%$ of all new car dealerships in the U.S. from January 1, 2001 to December 31, 2008. The data were collected by a major market research firm, and include every new and used vehicle transaction that occurred at the dealers in the sample. For each transaction, we observe the date and location of the purchase, information about the vehicle purchased, and the price paid for the vehicle. Our locations are defined by Nielsen Designated Market Areas (DMAs), which divide the U.S. into approximately 200 areas. DMAs are defined to correspond to media markets, which means that DMAs corresponding to major cities will have higher populations than DMAs in more rural regions. Examples of DMAs in our data include Phoenix, Arizona; Tulsa, Oklahoma; Lansing, Michigan; and Billings, Montana. ${ }^{1}$

We add to these data information about local weather. The weather data were collected by first using wolframalpha.com to find the weather station nearest to the principal city in each DMA. Weather data themselves were obtained for each weather station from Mathematica's WeatherData

\footnotetext{
${ }^{1}$ A list of all the DMAs covered by our data is available from the authors.
} 
compilation. ${ }^{2}$ Data were collected on temperature, precipitation, precipitation type, and cloud cover. Temperature is measured as the daily high temperature, measured in degrees Fahrenheit.

Precipitation is measured as the cumulative liquidized inches in a day. If the only precipitation type reported for the day is rain, we classify the precipitation as rainfall (measured in inches). If the only precipitation type reported during the day is snow, we classify the precipitation as snowfall (measured in liquidized inches). If both rain and snow are reported on a day, we classify the precipitation as slushfall (measured in liquidized inches). Cloud cover is a daily measure of the fraction of the sky covered by clouds.

The data show that vehicle transactions occur all year round, but are most common during the summer months. Of primary interest in this paper is the seasonal trend in convertible and 4-wheel drive purchases. In Panel A, of Figure A1 in the online appendix, we illustrate the percentage of total vehicle transactions that are convertibles by month of the year. Overall, convertibles make up between 1.5 and 3\% of total vehicles purchased. The data show a strong seasonal pattern in which the percentage of vehicles sold that are convertibles is highest in the early spring, peaking in April in seven out of the eight years in the data. While springtime is the most popular time to buy a convertible, the percentage of vehicles sold that are convertibles is still relatively large in the winter months. The annual winter troughs in this percentage are well over half the magnitude of the corresponding spring peaks. We note that these seasonal differences in convertible purchases are consistent with a standard model of state-dependent preferences: consumers who buy a convertible in the spring will be able to consume immediately several months of warm-weather driving while fall buyers will have to wait a few months to consume their convertible in its ideal weather. This makes the total discounted utility for spring convertible buyers higher than that of fall convertible buyers.

Similarly, Panel B of Figure A1 in the online appendix illustrates the percentage of total vehicle transactions that were 4-wheel drive vehicles by month and year. 4-wheel drive transactions range between $20 \%$ and $35 \%$ of total vehicle transactions. Panel B shows a seasonal pattern in which 4 -

\footnotetext{
2 If the weather station did not have weather data available for at least $90 \%$ of the 4745 daily observations between 1997 and 2010, data for the second- or third-closest weather station was used for that DMA. (There are 21 DMAs that use data from the second-closest station, and 6 that use data from the third-closest station.)
} 
wheel drive vehicles are particularly popular in the early winter months (purchases usually peak in December). ${ }^{3}$ As was the case for convertibles, this is not yet strong evidence for intertemporal bias since a standard model of state-dependent preferences would predict that the discounted utility of a 4-wheel drive is highest at the beginning of the winter.

One might expect that the seasonal sales patterns of the two different types of vehicles would differ with geography because of differences in climate. If we divide our DMAs into two groups, those with above-median monthly temperature variation ${ }^{4}$ (such as Chicago) and those with belowmedian monthly temperature variation (such as Miami), we do see differences between the groups, but the overall patterns are similar. Perhaps surprisingly, the overall percentage of convertibles purchased in these two types of DMAs is not too different. However, it is clear that the amount of seasonal variation in the percentage of vehicles sold that are convertibles is higher in the variabletemperature DMAs. For 4-wheel-drive vehicles, there is a large level difference in the percentage of such vehicles purchased in the two types of DMAs, and once again the variable temperature areas appear to have a more pronounced seasonal pattern. (Figure A2 in the online appendix shows these differences.)

Our identification strategy involves testing whether idiosyncratic weather conditions (controlling for time of year in order to eliminate seasonal purchasing patterns) are correlated with variation in the sales share of convertible and 4-wheel drive vehicles. To do this, we create indicator variables for each transaction denoting whether the vehicle purchased was a convertible or whether it was a 4-wheel-drive. Regressing these indicators on measures of the weather in the DMA where the transaction occurred will enable us to test whether atypical weather leads to variation in convertible and 4-wheel drive purchases.

Note that our estimates will identify the effect of weather on the equilibrium sales of vehicles of different types. In other words, we will estimate not only the effect of weather on vehicle demand, but also the effect of any actions dealers take in response to their perception of increased demand

\footnotetext{
${ }^{3}$ There is a mid-summer peak in 2005 which arose from record sales during GM, Chrysler, and Ford's employee discount pricing promotions. (Busse, Simester, and Zettelmeyer (2010) describe the effect of these promotions.)

${ }^{4}$ For each DMA, we calculate the variance of month-by-month average temperature data. DMAs are then classified as above the median if their temperature variance is larger than the median temperature variance in the sample.
} 
for certain types of vehicles under particular weather conditions. Of course, if there is a supply effect, that is evidence that dealers believe consumers have systematic behavioral biases, and respond accordingly. Our estimates identify the combined effect of changes in consumers' behavior and dealers' responses to those changes. ${ }^{5}$

\section{Estimation of Weather Effects on Vehicle Purchasing}

In this section, we estimate the effect of local, daily weather on the types of vehicles purchased. We begin by estimating the effect of weather on convertible purchases, and then on 4-wheel-drive purchases.

\subsection{Effect of Weather on Convertible Purchases}

We estimate the effect of weather on convertible sales using the following specification:

$$
I\left(\text { Convertible }_{\text {irt }}=\alpha_{0}+\boldsymbol{\alpha}_{\mathbf{1}} \text { Weather }_{r t}+\mu_{r T}+\tau_{Y}+\epsilon_{\text {irt }} .\right.
$$

$I($ Convertible) is an indicator variable that is equal to 1 if the vehicle sold in transaction $i$ in DMA $r$ on day $t$ was a convertible. Weather is a vector of weather variables for DMA $r$ on day $t$ - temperature, rainfall, snowfall, slushfall and cloud cover-defined in the previous section. (Summary statistics can be found in Table 1.) $\mu_{r T}$ are DMA*week-of-the-year fixed effects and $\tau_{Y}$ are year fixed effects. $\mu_{r T}$ will absorb the average seasonal variation in convertible sales at the week level, separately for each DMA. $\tau_{Y}$ will absorb year-to-year changes in consumer tastes for convertibles. ${ }^{6}$

Our main coefficients of interest will be $\boldsymbol{\alpha}_{\mathbf{1}}$, the vector of weather coefficients. Each element of $\boldsymbol{\alpha}_{\mathbf{1}}$ can be interpreted as the effect of a one-unit change in the corresponding weather variable on the probability that a particular transaction is a convertible, or-more suitably for our applicationon the fraction of vehicles sold on a given day that are convertibles.

\footnotetext{
${ }^{5}$ In the extreme, the effect could be driven entirely by the supply side if, for example, salespeople enjoy test-driving convertibles on sunny days, and buyers are influenced by the salesperson's extra effort. In order for the only effect to be a supply side effect, buyers would have to be immune to the effect of good weather that makes salespeople want to test drive convertibles on sunny days.

${ }^{6}$,In order to be able to use very granular fixed effects, we estimate linear probability models rather than Probit or Logit models.
} 
Table 2 reports the results of estimating Equation (1). Column 1 indicates that when the temperature is 1 degree higher than expected in a given DMA, the DMA experiences on average a 0.007 percentage point increase in the fraction of total vehicles sold that are convertibles. Thus a day with a temperature that is 10 degrees higher than average for that DMA in that week of the year would be predicted to see 0.07 percentage point more convertibles sold as a percentage of the total number of vehicles sold. ${ }^{7}$ This would be a $2.7 \%$ increase relative to the weighted base rate of $2.6 \%$ of vehicles sold being convertibles. Liquid inches of rain, snow, and slushfall all have negative effects on the fraction of vehicles sold that are convertibles, although these effects are relatively small given the amount of variation in rain, snow, and slushfall that exists in the data. Cloud cover is also very important for convertible sales. As the sky goes from completely clear to completely cloudy, convertible sales as a fraction of total vehicles sold decreases by 0.126 percentage points. Thus, a clear sky (relative to completely overcast) increases convertible sales by the same amount as approximately 18 degrees higher temperature.

The next four columns in Table 2 estimate the effect of temperature and other weather variables on convertible sales by quarter of the year. The effect of temperature is large and statistically significant in quarters 1, 2, and 4, but smaller in quarter 3. During quarter 3 (July, August, September), the baseline temperature is already quite warm in most areas, which may explain why an increase in temperature has less effect on convertible sales than in other quarters. We find it particularly noteworthy that high temperatures continue to have a fairly large effect on convertible sales in quarter 4 (October, November, December) since this is the time of year when the rational discounted utility of buying a convertible should be the lowest. Cloud cover-which is arguably important no matter what time of year-has a large and significant effect in all quarters (including quarter 3).

The differences across quarters in the estimated effects of temperature on convertible purchases suggest that the effect might be heterogeneous across the range of temperature. In order to assess

\footnotetext{
${ }^{7}$ We use a 10-degree change in temperature as a benchmark to help understand the size of the effects that we find. How does 10 degrees compare to typical temperature fluctuations? The standard deviation for temperature within a DMA and week of the year is 7.87 degrees. A 10-degree higher or lower temperature than average for a DMA and week of the year occurs approximately $20 \%$ of days.
} 
the extent of this heterogeneity, we re-estimate Equation (1), replacing the linear measure of temperature with indicator variables for the 5-degree bin into which the daily high temperature falls. We use 15 indicator variables for temperatures in bins from (25-29.9) to (95-99.9). We group all days with daily highs of 100 degrees or more into a single indicator, and leave days with high temperatures below 25 as our left-out group.

We report the estimated coefficients of these indicator variables graphically in Figure 1. For each bin, we plot the estimate coefficient as a dot, with "whiskers" representing the $95 \%$ confidence interval around the estimated coefficient. Higher temperatures increase the percentage of transactions that are convertibles fairly steadily from temperatures below 25 degrees up until some point between 70 and 80 degrees. At that point, the effect flattens out, suggesting that beyond 80 degrees, higher temperatures are no longer associated with increases in the share of vehicles sold that are convertibles.

\subsection{Effect of Weather on 4-Wheel-Drive Purchases}

While buying a convertible may seem especially attractive on a warm day, it is cold and snowy days that make 4-wheel drive vehicles seem like an especially good idea. Table 3 presents our estimates of the impact of weather variation on the percentage of vehicles sold that are 4-wheel drives. We obtain these estimates by substituting I(4WheelDrive), an indicator for whether a given transaction was for a 4-wheel drive vehicle, on the left hand side of Equation (1) to obtain the following estimation equation:

$$
I\left(4 \text { WheelDrive }_{i r t}=\beta_{0}+\boldsymbol{\beta}_{\mathbf{1}} \text { Weather }_{r t}+\mu_{r T}+\tau_{Y}+\epsilon_{\text {irt }} .\right.
$$

I(4WheelDrive) equals 1 if transaction $i$ that occurred in DMA $r$ on day $t$ is for a 4 -wheel-drive vehicle. All other variables are as defined for Equation (1). Our main coefficients of interest will be $\boldsymbol{\beta}_{\mathbf{1}}$, the vector of coefficients that represent the effect of weather on the fraction of vehicles sold in a given DMA on a given day that are 4-wheel-drive. The results are reported in Table 3.

As we expected, the results we find are roughly the opposite of what we found for convertibles. We find that colder temperature values lead to more 4-wheel drive purchases. For example, on a day 
with temperatures that are 10 degrees below the average for that DMA and week of year, the estimated coefficient predicts that the fraction of vehicles sold that are 4-wheel-drives would be 0.32 percentage points higher than otherwise. This represents a $.85 \%$ increase relative to the weighted baseline of $33.5 \%$ of vehicles sold with 4 -wheel drive. We also find a large, positive effect of snow and slush on 4-wheel drive transactions. One inch of liquidized snow (about 10 inches of snow) leads to a 1.81 percentage point increase in the percentage of total vehicles sold with 4-wheel drive. The effects for snowfall are statistically significant in quarters 1 and 4 . The effect size in quarter 2 is still reasonably large, but the standard error is also much higher than in quarters 1 and 4 . The impossibly large effect estimated for quarter 3 and its accompanying large standard error is clearly driven by the lack of snowfall variation that exists in the data during quarter 3. The effect of snowfall is slightly larger in quarter 4 than in quarter 1 . However, the significant effect of snowfall in quarter 1 suggests that even a snow storm that occurs towards the end of the winter season can have a powerful impact on 4-wheel drive purchase behavior.

As we did when analyzing convertible purchasing, we want to allow the effect of temperature to be nonlinear in its effect on 4-wheel drive purchasing. We do this by re-estimating Equation (2), replacing the linear measure of temperature with indicators for the same 5-degree bins reported in Figure 1. We report the estimated coefficients on these indicator bins graphically in Figure 2. As in Figure 1, the dot represents the estimated coefficient and the "whiskers" represent the 95\% confidence interval. The results in Figure 2 indicate that changes in temperature have little effect on 4-wheel drive purchasing for temperatures above 50 degrees. However, for temperatures below that, each 5-degree drop in temperature significantly increases the percentage of vehicles purchased that are 4-wheel drives.

While our estimates show that the fraction of vehicles sold that have 4-wheel drive rises in cold and snowy weather, this does not necessarily mean that the total number of 4-wheel drive sales rises. One way we could obtain our results is if total vehicle sales fall in cold, snowy weather, but sales of non-4-wheel drive vehicles fall by more than the sales of 4 -wheel drive vehicles. We investigate whether this is the case by aggregating the data to the day level and regressing the log of the number 
of convertibles sold and the log of the number of 4-wheel drives sold during that day on our weather measures. The result show that on warm, sunny days the total number of vehicles sold rises, but the number of convertibles sold rises by even more, which is why the percentage increases. Unit sales of 4-wheel drives, however, fall on cold snowy, days, but by proportionally less than purchases of vehicles without 4-wheel drive. Thus, it is worth noting that the 4-wheel drive results are driven in part by a drop in overall volume. After a snow storm, an individual who is going to purchase a 4wheel drive vehicle appears to be more motivated go to the dealership than buyers of non-4-wheel drive vehicles.

\subsection{Effect of Weather on Vehicle Prices}

We have shown in the previous two subsections that weather affects the equilibrium sales of vehicles of different types. Specifically, we have shown that the percentage of vehicles sold that are convertibles is higher on days with warm and sunny weather, while the percentage of vehicles sold that are 4-wheel drives are higher on days with cold, snowy weather. In this section, we investigate the effect of weather on the equilibrium prices of these types of vehicles.

The most intuitive way to explain in supply-and-demand terms our estimated effects of weather on purchasing is that weather causes a change in daily demand for different vehicle types. If this is so, what effect would we expect weather to have on equilibrium prices? The answer depends, of course, on the shape of the supply curve. ${ }^{8}$ In a simple supply and demand model, if the demand curve shifts out while an (upward-sloping) supply curve stays fixed, one would expect to see both higher prices and higher sales quantities.

There are several ways in which this simple model is not an ideal fit for the car industry. First, from a dealer's perspective, the supply of vehicles is not upward-sloping. Dealers can order vehicles from manufacturers at a fixed, per unit invoice price in whatever quantity they wish. This corresponds to horizontal marginal cost curve for the dealer. If the dealer is selling vehicles in a

\footnotetext{
${ }^{8}$ See Busse (2012) for a discussion of how different supply relationships affect the equilibrium price and quantity that arise from changes in demand.
} 
competitive market, the effect of an increase in demand should be increased sales, with essentially no increase in price. ${ }^{9}$

Second, a competitive price-taking market is not a very good description of the retail car industry. Individual consumers negotiate a price for a specific vehicle with the dealer. Whether the incremental buyers who enter (or leave) the market in response to a change in weather will obtain higher prices or lower prices than the inframarginal buyers who are in the market at all times depends on the reservation prices and bargaining characteristics of the incremental buyers relative to the inframarginal buyers. One might argue that the incremental buyers must have higher reservation prices than buyers on average, because they are being strongly swayed by temporary weather conditions. Similarly, one might argue that consumers who can buy "on impulse" must have high liquidity, and therefore likely higher incomes and higher reservation prices, than inframarginal buyers.

On the other hand, one might argue that if incremental buyers are buying this vehicle because of the weather (but would not be buying it on a day with different weather), the weather must have nudged them just above their point of indifference about buying. In this case, they might well have lower reservation prices than inframarginal buyers. Similarly, if dealers recognize which buyers are the incremental buyers who have come into the dealership because of the temporary weather condition, they may realize that they must offer a good price today or lose the sale forever, since in another few days the weather will change and these buyers will no longer be in the market. ${ }^{10}$

Overall, we conclude that it is an empirical question whether prices for convertibles and 4wheel drives will be higher on the same days that warm and sunny weather or cold and snowy weather leads to an increased sales share of these types of vehicles. We estimate the effect of weather on the prices of convertibles and 4-wheel drives using the following specification.

$$
\text { Price }_{i j t}=\gamma_{0}+\gamma_{1} \text { Weather }_{r t}+\gamma_{2} \text { PurchaseTiming }_{i t}+
$$

\footnotetext{
${ }^{9}$ Dealers place orders for vehicles months in advance, so over a horizon of several months, a dealer's supply of vehicles is predetermined. However, dealers can sell more or fewer vehicles on any given day, meaning daily vehicle supply is not fixed. (For more on how dealer supply and inventory affects prices, see Zettelmeyer, Scott Morton, and Silva-Risso (2007)).

${ }^{10}$ We thank Glenn Ellison for suggesting this point.
} 


\section{$f\left(\right.$ Odometer $\left._{i}, \boldsymbol{\gamma}_{3}\right)+\mu_{r T}+\tau_{Y}+\phi_{j}+\epsilon_{i j r t}$}

Price measures the price paid in transaction $i$ for vehicle $j$ that occurred on day $t$ in DMA $r$. (In order to make our measure of price represent a customer's total wealth outlay for the vehicle, we define price as the contract price for the vehicle agreed upon by the consumer and the dealer, minus any manufacturer rebate the buyer received, plus any loss (minus any gain) the consumer received in negotiating a price for his or her trade-in.) Weather is a vector containing the temperature, rainfall, snowfall, slushfall, and cloud cover on day $t$ in DMA r. PurchaseTiming is a vector containing indicators for whether transaction $i$ occurred during the weekend, or at the end of the month, times in which salespeople may be willing to sell vehicles at a discount in order to hit sales volume targets. The specification also includes DMA*week-of-year $\left(\mu_{r T}\right)$, year $\left(\tau_{Y}\right)$, and "vehicle type" $\left(\phi_{j}\right)$ fixed effects. (A vehicle type is defined by the interaction of make, model, model year, trim level, doors, body type, displacement, cylinders, and transmission.) We estimate Equation (3) separately for new convertibles, used convertibles, new 4-wheel drives, and used 4-wheel drives. The specifications that estimate the effect of weather on used vehicle prices also include a linear spline in the vehicle's odometer with knots at 10,000-mile increments, which allows vehicle prices to depreciate over time in a reasonably flexible way.(See Busse, Knittel, and Zettelmeyer (2013) for use of a similar specification to estimate price effects in similar data.)

Table 4 reports the results of estimating Equation (3). Generally speaking, we find that the effect of weather on prices is fairly small, even when it is statistically significant. In Column 1, which estimates the effect of weather on new convertible prices, none of the weather variables have statistically significant effects. We do not find any evidence of weather affecting the transaction prices of convertibles. The weather coefficients, reported in column 1 for new convertibles and in column 2 for used convertibles are both small and statistically insignificant. For 4-wheel drives, the results are similarly small. In column 3 , we estimate that cloud cover leads to a statistically significant increase in the price of new 4 -wheel-drives, but by only $\$ 21.69$ for a change from completely clear to completely overcast skies. For used 4-wheel-drives, in column 4, we estimate that one inch of rainfall increases the average transaction price by $\$ 6.95$, and that cloud cover reduces the price by $\$ 23.79$, 
the latter result being in the opposite direction of what we would expect. In addition to being statistically insignificant, these effects are very small compared to average transaction prices of $\$ 31,845$ for new 4-wheel-drives and $\$ 19,132$ for used 4-wheel-drives.

\section{Rational Explanations for Weather Effects}

In this section, we consider several potential explanations for the weather effects we estimate that do not rely on any psychological mechanisms. First, we consider whether our estimated weather effects are the result of short-term intertemporal shifts in demand. For example, it could be that consumers who have decided to buy a convertible may wait for a nice day to actually make the purchase. Second, we consider whether consumers are more likely to purchase a vehicle with a weather-related characteristic such as a convertible roof or 4-wheel drive on a day whose weather enables them to test drive the vehicle in that weather. Third, we consider whether consumers who test-drive a convertible or a 4-wheel drive on a day with the complementary weather learn thereby about their utility for the vehicle type and that this is what drives the increased fraction of convertible and 4-wheel drive sales on the relevant weather days.

\subsection{Shifts in Purchase Timing}

Our results in Section 3 indicate that the fraction of vehicles sold on a given day that are either convertibles or 4-wheel drives is influenced by daily weather variation. One possible explanation for this empirical finding is that weather fluctuations may appear to be incrementally increasing purchases of certain types of vehicles, but instead just cause short-run intertemporal substitutions in vehicle purchasing behavior. In other words, weather shifts when, but ultimately not what, people buy. An example of this "harvesting" story is that a consumer may be interested in purchasing a convertible sometime in the next month and then actually makes her purchase whenever it happens to be a nice day outside. ${ }^{11}$ Our previously noted finding that atypically warm weather in November

\footnotetext{
11 The fact that more convertibles are bought in spring than winter and the reverse for 4 -wheel drive vehicles suggests that there may be harvesting in response to the overall seasonal pattern of the weather. However, this does not mean that harvesting happens in response to idiosyncratic weather variation.
} 
can affect convertible purchases and a snow storm in February can affect 4-wheel drive purchases casts doubt on harvesting as the sole cause of our results. However, these end-of-season purchases cannot rule out harvesting entirely as a contributing factor to our results.

In order to assess the extent to which there is short-run intertemporal substitution of purchases with respect to daily weather fluctuations, we estimate a distributed lag model. We do so by reestimating Equations (1) and (2) with 60 daily lags of each weather variable added to the estimating equation.

$$
\begin{aligned}
& \text { (4) } I\left({\text { Convertible })_{i r t}=}_{0}+\boldsymbol{\alpha}_{\mathbf{1}} \text { Weather }_{r t}+\sum_{j=1}^{60} \boldsymbol{\alpha}_{\mathbf{1 , - j}} \text { Weather }_{r, t-j}+\mu_{r T}+\tau_{Y}+\epsilon_{\text {irt }}\right. \\
& \text { (5)I(4WheelDrive })_{i r t}=\beta_{0}+\boldsymbol{\beta}_{\mathbf{1}} \text { Weather }_{r t}+\sum_{j=1}^{60} \boldsymbol{\beta}_{\mathbf{1},-j} \text { Weather }_{r, t-j}+\mu_{r T}+\tau_{Y}+\epsilon_{i r t}
\end{aligned}
$$

Weather $_{r, t-j}$ is the vector of weather variables (temperature, rainfall, snowfall, slushfall, and cloud cover) $j$ days before the transaction date. $\boldsymbol{\alpha}_{\mathbf{1},-\boldsymbol{j}}$ and $\boldsymbol{\beta}_{\mathbf{1}, \boldsymbol{j}}$ are vectors of coefficients that estimate the effect of weather $j$ days ago on day $t$ purchases of convertibles and 4 -wheel drives, respectively. ${ }^{12}$ By including lagged variables, we are able to test whether having cold or hot days leading up to the day of purchase influences how the current weather affects behavior. For example, in the convertible scenario, negative coefficients on the lag variables would be interpreted as evidence of harvesting via the following argument. A negative coefficient on, say, the three day lag of temperature would indicate that if the weather three days ago was hot, sales today are lower by some amount than they otherwise would have been. This implies that if the weather today is hot, sales three days from now will be lower by that same amount. We can thus use the lag coefficients to answer the question "If the weather is hot today, how much lower will sales be in subsequent days?" The one day lag gives us an estimate for the effect of hot weather today on sales one day from now, the two day lag estimates the effect of hot weather today on sales two days from now, and so on. Thus, if we add up all our lag coefficients and find that they equal the negative of the current period coefficient, it suggests that any increased sales that occur due to hot weather this week are made up entirely of

\footnotetext{
12 This specification is identical to instead regressing the weather variables on the fixed effects, obtaining residual values, and then including lag weather residual values in the regression.
} 
sales displaced from the following 60 days. More generally, the sum of the lag coefficients tells us how much of our estimated current period effect is due to intertemporal substitution. ${ }^{13}$

Figures 3 and 4 present the results of this dynamic analysis for convertible purchases estimated by Equation (4). Figure 3 plots the estimated coefficient and confidence intervals for the current day's temperature (daily lag $=0$ ) and for 60 daily lags of temperature. Figure 4 plots the coefficient and standard errors for the current day's cloud cover and 60 daily lags of cloud cover. The results once again show a large and significant effect of current weather on convertible purchases. The estimated coefficient on the current day's high temperature is 0.005 , with a standard error of 0.0006 , similar to the coefficient of 0.007 reported in Table 2. The coefficients on the lag variables are all small relative to the current temperature coefficient, and all but four of the 60 lag coefficients are statistically insignificant. Most importantly for the question at hand, more of the coefficients are positive than negative, especially among the most recent two or three weeks of lags. The sum of the 60 lag coefficients is 0.012 ; if our estimated warm weather effect were intertemporal shifts in sales, the coefficients would be expected instead to sum to the negative of the current day coefficient of 0.005. We can test the null hypothesis that the sum of the first $X$ lags are equal to the negative of the current day coefficient by imposing this as a linear restriction on the estimation. If we do so, we reject this null hypothesis with a $\mathrm{p}$-value $<0.001$ for $X$ equal to $7,14,21,28$, 45, or 60 days of lags. If anything, it appears that warm weather over the past several weeks leads to an even higher fraction of vehicles sold today being convertibles.

Figure 4 shows the estimated coefficients for the current day's cloud cover and 60 daily lags of cloud cover. In this specification, the estimated coefficient on the current day's cloud cover is -0.125 with a standard error of 0.013 , almost identical to the -0.126 reported in Table 2 . The sum of the 60 lag coefficients is 0.199 , which means that we cannot conclude that the cloud cover effects on convertible sales are not due to short-term shifts in purchase timing. However, most of the positive lag coefficients that contribute to this result are in the longer lags. We can reject that the sum of the

\footnotetext{
${ }^{13}$ See Jacob, Lefgren, and Moretti (2007) for a similar analysis that tests for intertemporal substitution of crime using weather shocks and Deschenes and Moretti (2009) who test for intertemporal substitution of mortality using weather shocks. See these papers also for a discussion of summing up coefficient values to test for evidence of intertemporal substitution.
} 
first $X$ lag coefficients equal the negative of the current day coefficient for $X$ equal to 7, 14, and 21 days with a p-value $<0.001$, and for 28 days with a p-value of 0.026 . For longer sums of lags, we cannot reject the null hypothesis that our results are due to intertemporal shifts in purchase timing. However, this means that, to the extent that our estimated result is the consequence of intertemporal shifts, it is shifts coming mostly from more than a month ago, not shifts coming from the previous several weeks.

Figures 5 and 6 provide a similar analysis for 4 -wheel drive purchases. Figure 5 shows the current day and 60 daily lag coefficients for temperature, while Figure 6 shows them for snowfall. The estimated coefficient of current day temperature on the fraction of vehicles sold that are 4wheel-drive is -0.015 , with a standard error of 0.0027 , which is somewhat smaller than the -0.032 reported in Table 3. We can reject at a p-value $<0.001$ that the sum of the lagged coefficients equal the negative of the current day coefficient over the 7-, 14-, 21-, 28-, 45- or 60-day horizon. The lag coefficients, while not statistically significant, are more suggestive that cold weather in the two or three previous weeks increases 4-wheel drive sales today.

The last set of distributed lag results is shown in Figure 6. The coefficients in this figure indicate that the current day's snowfall has a positive and significant effect on the fraction of vehicles sold today that are 4-wheel drive vehicles, but so does snowfall on almost any of the days of the previous two weeks. These coefficients are not consistent with shifts in purchase timing that would explain our empirical result from Section 3. (We can again reject at a $\mathrm{p}$-value $<0.001$ that the sum of the lagged coefficients equal the negative of the current day coefficient over the 7-, 14-, 21-, 28-, 45- or 60-day horizon.) Instead, the results here suggest that while a snowstorm today has the biggest effect on sales today, it will contribute to an increased fraction of sales of 4-wheel drive vehicles for almost two weeks.

\subsection{Test Drive Timing}

One aspect of vehicle purchasing that may lead to a correlation between weather and vehicle purchase timing, particularly for convertibles, is the desire of most customers to test drive a vehicle 
before buying. Suppose a customer is considering buying a convertible, and that she is able to forecast accurately her long-term utility from owning a convertible. Now suppose that, before she buys the convertible, she would like to be able to test out various features of the convertible: how convenient it is to put the top up and down, how much wind or road noise she experiences with the top down, etc. It is unpleasant to do such a test drive when the weather is cold, so she waits for a warm day to go to the dealership, test drive, and ultimately purchase the convertible. Alternatively, suppose that another customer suddenly needs a replacement vehicle, perhaps because his current vehicle has broken down and is no longer worth repairing. Suppose that a convertible is one of the vehicles he would consider purchasing, but on the day he needs the new vehicle it is too cold to test drive a convertible. Unwilling to buy the convertible without being able to test out the convertible features of the car, he buys a non-convertible instead.

The behavior of both of these types of customers would lead to a higher percentage of vehicles sold on warm days being convertibles relative to the percentage on cold days for reasons other than errors in forecasting intertemporal utility. The first type of customer that we outlined above would lead to harvesting (customers wait until a warm week to buy a convertible so that they can test drive the vehicle). In the previous section, we already discussed and ruled out harvesting effects for convertibles with regards to temperature and also with regards to cloud cover within a four-week window. However, the second customer type that we discuss above is not ruled out by our distributed lag model. Several pieces of evidence, however, argue against a test drive learning story. For example, Figure 1 indicates that an extra degree of warm weather results in more convertible purchases even when the baseline temperature is in the 60-80 degree range. This is a range of temperature for which it is clearly possible for someone to test out the convertible features comfortably. Our results thus suggest that it is more than simply testing the features of a car that cause warm weather to result in a higher fraction of convertibles being sold.

We can also get a sense of how important test drive timing might be for our results by considering the effect of cloud cover. There is no reason that a customer could not test drive a convertible on a day that is cloudy — as long as it is not cold or rainy. Thus, in our regressions, which 
control for temperature and rain, we should not see an effect of cloud cover if the reason for the correlation between temperature and convertible purchases is test drives. However, psychological mechanisms which cause consumers to over-respond to current mental and emotional states should lead to warm, sunny days being days on which people are particularly likely to buy convertibles, rather than warm, cloudy days. Indeed, if we examine the results in Table 2, we find that unusually cloudy days have a significant negative effect on the percentage of vehicles sold that are convertibles, consistent with one of several psychological mechanisms. It is particularly noteworthy that cloudy days have a statistically significant negative effect in all four quarters, and the effect of cloudy days is largest in the third quarter, when days are generally warm. This third quarter effect is especially suggestive of the fact that people buy more convertibles on warm, clear days not because it is more possible to test drive them, but because it seems more attractive to own a convertible on such days.

\subsection{Consumer Learning}

Another alternative hypothesis that would explain our findings is that customers need to test drive a vehicle with weather-related features on a day that has the relevant weather (warm and sunny or cold and snowy) in order to actually learn what their utility will be from owning either a convertible or a 4-wheel drive in such weather conditions. Under this hypothesis, a warm, sunny day does not lead a customer to overestimate the utility she will get from owning a convertible; instead it enables her to learn for the first time how high her true utility will be from owning a convertible in such weather states. Before considering this as an alternative hypothesis, we note that this type of extreme learning story-in which vehicle buyers can't quite imagine what it would be like to own this vehicle in another state of the world even when they have experienced that state of the world many times-is in itself an impediment to correctly forecasting intertemporal utility. As such, learning is a rational mechanism that, in its extreme form, is very closely related to the psychological mechanisms that we discuss in the next section. 
Despite the similarity between learning as described above and psychological biases, our data allow us to investigate somewhat more direct evidence for learning as an explanation. In our data, we observe what trade-in, if any, customers bring when they buy a vehicle. This means we can observe vehicle transactions by customers whom we know have owned already either a convertible or a 4-wheel drive vehicle. Previous convertible owners are less likely to need to "learn" about what it is like to drive a convertible during a warm weather state, and similarly for previous 4-wheel drive owners and cold or snowy states, so evidence that idiosyncratic weather impacts these consumers is particularly strong evidence against learning as an explanation.

If we look within the subset of transactions that use a convertible as a trade-in, we find that approximately $25 \%$ of these consumers purchase another convertible while $75 \%$ purchase a nonconvertible vehicle. Column 1 of Table 5 reports the results of our baseline specification if we restrict the sample to consumers who are trading in a convertible. While the standard errors are much larger due to the sample restriction, we continue to find a positive impact of temperature at the time of purchase on convertible sales. The point estimate is about six times larger than the point estimate in the entire sample_although the larger estimate in percentage point terms is comparable in percentage terms because the convertible purchase rate in this sample $(25 \%)$ is so much higher. ${ }^{14}$

In Column 2 of Table 5, we estimate the effect of weather on consumers who are trading in a 4wheel drive vehicle. Overall, $78 \%$ of people who trade in a 4 -wheel drive vehicle purchase another 4-wheel drive vehicle. In Column 2 we continue to find strong and statistically significant effects of all five weather measures on 4-wheel drive purchases for buyers who traded in a 4-wheel drive vehicle. The estimated effects are substantially smaller in percentage terms than in the full sample, in large part because the unconditional probability of buying a 4-wheel drive vehicle is so high in this sample. ${ }^{15}$

\footnotetext{
14 The full sample results indicate that a 20 -degree increase in temperature increases the percentage of vehicles sold that are convertibles by 0.14 percentage points in the full sample, a $5.4 \%$ increase relative to a base percentage of $2.6 \%$. In the "convertible trade-in" subsample, the effect is a 1.3 percentage point increase, a $5.2 \%$ increase relative to a base percentage of $25 \%$.

${ }^{15}$ The full sample results indicate that a 20-degree decrease in temperature increases the percentage of vehicles sold that are 4-wheel drive by 0.64 percentage points in the full sample, a $1.9 \%$ increase relative to a base percentage of $33.5 \%$. In the "4-wheel drive trade-in" subsample, the effect is a 0.86 percentage point increase, a $1.1 \%$ increase relative to a base percentage of $78 \%$. The full sample results indicate that 1 liquidized inch of snowfall increases the percentage of vehicles
} 
The fact that we find effects of idiosyncratic weather variation in precisely the subsample of buyers who would seem to have the least to learn about their utility from owning either a convertible or a 4-wheel drive vehicle casts doubt on the learning story being a key explanation of the effects that we find. ${ }^{16}$

\section{Psychological Mechanisms}

In the previous two sections, we provided evidence that vehicle consumers are highly sensitive to the weather on the day of purchase, effects which cannot be justified by a standard model of consumer choice and cannot be explained by a variety of other rational mechanisms such as purchase timing or learning. In this section we explore psychological theories that predict being overly sensitive to the state of the world at the time of purchase. We focus on projection bias and salience as the two most likely candidates and separately discuss the evidence against and in favor of each of these mechanisms. ${ }^{17}$

\subsection{Projection Bias}

Projection bias has received significant attention in the economics and psychology literature. This bias, which is based on earlier psychological work, was formalized by Loewenstein, O’Donoghue, \& Rabin (2003). In their model, Loewenstein, O’Donoghue, and Rabin assume that a person has statedependent utility such that her instantaneous utility of consumption, $c$, in state, $S$, can be

sold that are 4 -wheel drives by 0.81 percentage points in the full sample, a $2.4 \%$ increase relative to a base percentage of $33.5 \%$. In the "4-wheel drive trade-in" subsample, the effect is a 1.07 percentage point increase, a $1.4 \%$ increase relative to a base percentage of $78 \%$.

16 These results also speak to a separate selection concern that one might have. Perhaps the primary reason why convertibles are more likely to sale on a sunny day is that consumers who like convertibles (and already own one) are more likely to be out shopping on a warm sunny day. This analysis restricts the sample to people who are driving the same type of car and thus helps ease this particular concern (in conjunction with some of the other evidence that we present like the results from the distributed-lag model).

${ }_{17}$ Two additional psychological theories that are worth mentioning include present-biased preferences and mood effects. In an earlier version of this paper, we provided a calibration that indicated that the level of impatience required to explain our effects are outside the range of parameter values typically found using a model of present-biased preferences. We also find no evidence that individuals simply purchase more expensive vehicles or sporty vehicles (e.g. coupe body style) on warm days, which are likely predictions of a mood-effect story. 
represented as $u(c, s)$. They then consider an individual who is currently in state $s^{\prime}$ who is attempting to predict her future instantaneous utility of consumption, $c$, in state $s: \tilde{u}\left(c, s \mid s^{\prime}\right)$. An accurate prediction would be represented by $\tilde{u}\left(c, s \mid s^{\prime}\right)=u(c, s)$.

Loewenstein, O’Donoghue, \& Rabin argue that projection bias causes agents' predictions about future utility to be unduly influenced by the state they are in at the time of the prediction. Specifically, an individual exhibits projection bias if

$$
\tilde{u}\left(c, s \mid s^{\prime}\right)=(1-\alpha) u(c, s)+\alpha\left(u\left(c, s^{\prime}\right)\right)
$$

where $\alpha$ is a number between 0 and 1 . If $\alpha=0$, then the individual accurately predicts her future preferences, whereas if $\alpha>0$, an individual perceives her future utility to reflect a combination of her true future utility along with the utility that consumption $c$ would provide in her current state $s^{\prime}$.

This simple model of projection bias can easily be extended to an intertemporal choice framework. Consider, for example, the utility that a person receives from purchasing a convertible at time $t\left(\operatorname{conv}_{t}\right)$ and owning it until period $T$. Her true utility can be represented by

$$
U^{t}\left(\operatorname{conv}_{t}, \ldots, \operatorname{conv}_{T}\right)=\sum_{\tau=t}^{T} \delta^{(\tau-t)} u\left(\operatorname{conv}_{\tau}, s_{\tau}\right)
$$

where $0 \leq \delta \leq 1$ is her standard discount factor. Once again, following Loewenstein, O’Donoghue, \& Rabin (2003), a person with projection bias perceives her intertemporal utility to be

$$
\widetilde{U}^{t}\left(\operatorname{conv}_{t}, \ldots, \operatorname{conv}_{T} \mid s_{t}\right)=\sum_{\tau=t}^{T} \delta^{(\tau-t)} \tilde{u}\left(\operatorname{conv}_{\tau}, s_{\tau} \mid s_{t}\right)
$$

where $\tilde{u}$ represents the perceived instantaneous utility described by Equation (9).

This framework illustrates that an individual's perceived intertemporal utility of purchasing a convertible at time $t, \widetilde{U}^{t}$, is overly influenced by $s_{t}$. Specifically, we would predict that when $s_{t}$ is a very good state of the world for consuming a convertible (warm, sunny weather), an individual has a higher perceived utility of owning the convertible than when $s_{t}$ is a bad state of the world for consuming a convertible (cold, cloudy weather). 
One question that arises from this model is whether or not individuals correctly anticipate the path of states $\left(s_{t}, \ldots s_{T}\right)$. It is possible that individuals are more likely to predict a greater number of warm-weather states in the future when the current weather is warm relative to when the current weather is cold. ${ }^{18}$ Loewenstein, O’Donoghue, \& Rabin (2003) assume that individuals correctly anticipate the path of states, but err when predicting the utility that those states combined with a given consumption will generate. In practice, these two errors (projection bias of utility and projection bias of states) both lead to similar incorrect predictions of future utility. Thus, it is difficult to separate these two different types of projection bias and our analysis does not attempt to do so. However, the prevalence of weather information that is available to people during the time of our study, including their own experience of local weather patterns, argues against projection bias of states as the underlying mechanism. It is much harder to find information about future utility than it is to find information about the likelihood of future weather states.

Unlike present-biased preferences, which require the entire weather-related effect that we find to be driven by consumers overweighing the value they place on consumption in the first day or two of owning the vehicle, projection bias suggests that consumers mispredict the value they will receive from owning the convertible in every future state of the world when the weather is different from the weather at the time of purchase. Because the bias impacts almost all periods rather than just one period, this model can more easily predict effects of the size that we find in this paper than a model of present-biased preferences. While we cannot conclusively determine that projection bias is the sole contributing factor in the results that we find, our results are consistent with this psychological model of behavior.

Conlin, O’Donoghue, and Vogelsang (2007) propose that one can test directly for projection bias by finding evidence of consumers deciding ex post that a decision was a mistake. Specifically,

\footnotetext{
18 Some psychological evidence suggests that being in a hot or cold state may make associated states of the world seem more likely in the future (see for example, Risen \& Critcher (2011) and Li, Johnson, and Zaval (2011)).
} 
projection bias suggests that people who make a choice in one state of the world may realize the mistake when the state of the world changes. Conlin, O'Donoghue, and Vogelsang (2007) test for such mistakes by analyzing whether cold-weather clothing (boots, gloves, etc.) purchased by mail order were more likely to be returned if the purchase was made during very cold weather. In the vehicle market, projection bias mistakes might be identified by seeing vehicles that were purchased on atypical weather days reappear in the market (either as trade-ins or as subsequent used car sales) more quickly than vehicles that were purchased on days when the weather was seasonally typical. The quick return of a vehicle to the market could indicate that the owner was not happy with the purchase he or she made.

Unfortunately, there are at least two reasons why testing for early returns in the vehicle market is much harder than for catalog orders. The first reason is simply a data limitation. Although our data are extensive and represent a 20\% sample of all new car dealerships in the U.S., we can only identify "returned" vehicles that happen to be traded in or sold as a used vehicle at one of the dealerships we observe. Said another way, for any vehicle whose sale we observe at some point, we have roughly a $20 \%$ chance of seeing that vehicle's subsequent return or resale if that transaction happens at a dealership, and no chance of seeing it if that transaction happens person-to-person. Second, and perhaps more importantly, car dealerships do not offer the kind of "no-hassle return" policies that are common for catalog retailers. A mistake that is made when buying winter gloves can be easily fixed with a few minutes and a little postage. However, an individual who realizes that he or she has made a mistake after buying a convertible cannot return it so easily. To switch the convertible for a hardtop will require the individual to sell the convertible (likely at a loss if the vehicle is new because of the rapid initial depreciation of new vehicles) and buy the hardtop (and again undergo the initial depreciation if the replacement vehicle is new). Thus, even if mistakes are being made, the mistakes may not be large enough to merit fixing.

Despite these two concerns, we test for the impact of weather at the time of purchase on how quickly the vehicle reappears in the market. Of the roughly 40 million vehicles that are transacted in our dataset, $2.37 \%$ of them reappear within 1 year as a trade-in or subsequent sale, $5.03 \%$ within 2 
years, and $7.16 \%$ within 3 years. ${ }^{19}$ On average in the U.S., owners keep their vehicles for just over 5 years (Polk, 2010).

Our empirical strategy is to estimate whether convertibles that were purchased when the weather was atypically warm and 4-wheel drive vehicles that were purchased when the weather was atypically cold are more likely to reappear in our data within a short time frame than vehicles purchased under more typical weather conditions. The columns of Table 6 report results for regressions in which the outcome variable is an indicator that equals one for a given transaction if we observe the transacted vehicle reappear in our data as a trade-in or in another sales transaction within, respectively, 1, 2, or 3 years. We control for DMA*week-of-year fixed effects to eliminate seasonal and geographic differences in how quickly vehicles are returned. Table 6 shows that convertibles are, overall, 1.272 percentage points more likely to be returned within a year than other types of vehicles; 4-wheel drive vehicles are also more likely to be returned (by 0.285 percentage points) than other types of vehicles. The positive signs of the coefficients estimated for the interaction of convertible and temperature variables are consistent with projection bias: convertibles are more likely to be returned quickly when they were purchased on days with atypically warm weather. However, this result is statistically significant only in column 2 . The point estimates suggest that when the weather is 10 degrees warmer than average for that DMA and week of the year, convertibles are 0.17 percentage points more likely to be returned within 2 years than hardtops (a $2.3 \%$ change relative to the baseline convertible return rate of $7.332 \%$ ). The temperature interaction with 4-wheel drive vehicles is more consistently statistically significant, and indicates that a 4-wheel drive vehicle is more likely to be returned within 1, 2, or 3 years if it is purchased on an atypically cold day. Overall, our results for the effect of weather on returning vehicles, while clearly suggestive, is less strong than our evidence for the effect on purchasing vehicles. An important constraint we face is that the number of vehicles we see sold and then see reappear within our data is simply not that high. As a consequence, we have limited ability to identify differences in the rates at which vehicles are returned under different circumstances.

\footnotetext{
${ }^{19}$ Unique identification numbers corresponding to individual VIN numbers are used to track vehicles over time.
} 


\subsection{Salience}

The second psychological mechanism that we consider in detail is salience. In a consumer context, salience refers to the idea that a customer's attention may be systematically directed towards certain features of a product and that those features will receive disproportionate weight in purchase decisions. The idea of salience is certainly not new in the psychology literature, but it has been formalized and received renewed attention in the last few years. (See, for example, Bordalo, Gennaioli, and Shleifer (2012a, 2012b) and Koszegi and Szeidl (2013).. $)^{20}$

To understand how salience could predict the effects that we find, we consider the formalization of salience provided by Bordalo, Gennaioli, and Shleifer (2012b). Their model predicts that consumers will place greater weight on product attributes that are salient at the time of purchase. The salience of an attribute is determined by how that attribute compares to the attributes of the products in a consumer's "choice context." The choice context includes the products among which a consumer can currently choose, the "choice set." ${ }^{21}$ In a dynamic setting, the choice context may also include products that the consumer expects to be available, even if those choices aren't currently available. For example, if prices have recently increased or decreased, products at their past prices could be part of the choice context. A consumer is assumed to have a "reference good" whose attributes equal the average of the attributes in the choice context. A particular attribute of a good is salient (and will therefore be weighed more heavily) when it differs by more from the reference good than other attributes do. For example, the price of a good will be more salient than the quality of a good if the price of the good is more different from the price of the reference good than the quality of the good is different from the quality of the reference good.

\footnotetext{
20 There have also been many recent empirical papers that find evidence of salience/attention. See, for example, Gabaix and Laibson (2006), Chetty, Looney, and Kroft (2009), Finkelstein (2009), Brown, Hossain, and Morgan (2010),

Malmendier and Lee (2011), Lacetera, Pope and Sydnor (2012), and Hastings and Shapiro (2012).

${ }^{21}$ The choice context could include only a subset of choices actually available if a consumer restricts attention to a "consideration set" instead of the full choice set.
} 
Hastings and Shapiro (2012) contains an application of this model. They consider whether salience can explain consumers' choices between gasoline grades that differ both in quality (octane rating) and price. They suppose that past prices inform consumers' price expectations and therefore are part of consumers' choice contexts when considering gasoline choices. ${ }^{22}$ Thus, if gasoline prices increase suddenly, the current prices of gasoline will differ substantially from the reference price for gasoline defined by the choice context, which includes the former, lower gasoline prices. This will increase the salience of prices, increasing the utility weight that consumers place on the price attribute relative to the quality attribute of gasoline, and thereby decreasing the premium they are willing to pay for higher octane gas relative to what they were willing to pay when the overall price levels were lower.

In Hastings and Shapiro (2012), as in many of the examples described in Bordalo, Gennaioli, and Shleifer (2012b), it is the value of the attribute itself which varies across contexts and causes the attribute's salience to vary (for example, gasoline prices at different points in time, wine prices at stores vs. restaurants, etc.). In our context, a convertible roof does not become "more convertible" in some contexts than others. Instead, there is another variable, weather, which varies over time and which can make the roof style of the car become more or less salient at different points in time.

Consider, for example, a situation in which a consumer is choosing between one of two cars: a high-priced convertible or a low-priced sedan. In a given purchase situation, a consumer may find the price to be the salient feature of the vehicle or may find the roof style to be salient. On a day with especially beautiful weather, having a convertible will seem particularly attractive compared to how it would seem on days with less nice weather. In this sense, the value of the convertible attribute today will be unusual compared to the value of the convertible attribute on "average" days,

\footnotetext{
${ }^{22}$ Hastings and Shapiro use the term "evoked set" to refer to a choice context, referring to the set of products that are evoked in a consumer's mind while she is considering a particular purchase decision.
} 
making it the salient feature, and making consumers value it more relative to price than on days with less good weather. ${ }^{23}$

Distinguishing between salience and projection bias. As a coarse generalization, both salience and projection bias would predict that there should be more convertibles sold on sunny days and more 4-wheel-drives sold on snowy days. Therefore, one might well ask if there is any way to distinguish whether salience or projection bias is a more likely explanation for the effects we have found. One difference between the mechanisms is that projection bias predicts that people will buy more convertibles when the weather is nice in an absolute sense, while salience predicts that people will buy more convertibles when the weather is unusually nice relative to some benchmark (since it is in comparison to the average that makes an attribute salient). Said another way, projection bias predicts something about the effect of weather "levels" while salience predicts something about the effect of weather "differences" or "surprises."

Whether this distinction enables us to tease apart these two potential mechanisms depends on what kinds of weather "surprises" one thinks are relevant for salience. One definition of a weather surprise would be weather that differs from the average weather at that time of year. In other words, consumers are surprised when the weather is different from the expectation they have formed based on their experience of weather in past years. Another definition of a weather surprise would be weather that differs from what the weather has been recently; in the last few days or weeks, for

\footnotetext{
${ }^{23}$ How product attributes are defined is an important part of specifying this model. If one defines the product attribute as "roof style" then both a warm, sunny day (which will make a convertible seem especially delightful to drive) and a cold, wet, blustery day (which will make a convertible seem drafty and unpleasant to drive) should make the roof style more salient, because both weather types will lead to a value of the roof type that is very different from the reference value. If the convertible style of the roof is the generally preferred style, then when weather makes it more salient, consumers should put more weight on roof style and be more willing to buy a convertible whether the increased salience arose from unusually good weather or unusually bad weather. This is inconsistent with our results, and probably inconsistent with most people's intuition. In order to have salience explain both increased sales of convertibles in good weather and decreased sales of convertibles in bad weather, we could define two product attributes that are associated with roof style: "enjoyableness" (an attribute experienced in good weather) and "draftiness" (an attribute experienced in bad weather). Good weather would make the "enjoyableness" attribute more salient (without affecting the salience of draftiness), leading to increased sales of convertibles on good weather days. Bad weather, however, would make the "draftiness" attribute more salient (without affecting the attribute of enjoyableness), and would lead to decreased sales on bad weather days.
} 
example. In this case, consumers would be surprised when the weather changes from what it has been recently. In terms of the formal model of Bordalo, Gennaioli, and Shleifer, the distinction is whether the reference good is "driving a convertible in weather that is typical for this time of year" or whether the reference good is "driving a convertible in the weather experienced over the last few days or weeks."

We cannot distinguish between projection bias and salience under the "surprise relative to expectations" interpretation. The reason for this has been described already in the paper. Summarizing briefly, weather follows a seasonal trend, which means that there is a very plausible discounted utility explanation for a correlation between weather and car sales. Therefore, we would not want to attribute a correlation in the seasonal pattern of weather and car sales to an intertemporal bias. The only empirical effect that we could attribute to a psychological bias (either projection bias or salience) is an effect of atypical weather on car sales (since a temporary weather fluctuation shouldn't affect the discounted utility of owning a long-lived durable good). Unfortunately, the correlation of atypical weather with car sales would be predicted by both mechanisms, and therefore doesn't enable us to distinguish between the two.

In contrast, under the "weather surprise relative to recent" interpretation of when particular attributes of a car should be salient, we may be able to distinguish between the two mechanisms. In the language of Bordalo, Gennaioli and Shleifer, suppose that the "choice set" part of a consumer's choice context includes both convertibles and non-convertibles on the day of purchase (with its associated weather) and the "expectations" part of the choice context includes the same vehicles in the days leading up to the actual purchase (which might have different weather states). If this is the case, then the roof style of a car should be particularly salient when the weather on the date of purchase is not only nice, but nice relative to the weather in the days leading up to the purchase. For example, if the weather was very cool and cloudy in the week leading up to the purchase, then warm 
and sunny weather on the day of purchase makes the convertible feature particularly unusual relative to the reference good in the choice context. Projection bias, on the other hand, does not predict that convertible sales would be higher on a good weather day that follows a string of bad weather days than on a good weather day that follows a string of other good weather days.

This prediction was tested in section 4.1 of the paper when we provided results from a distributed lag model. ${ }^{24}$ We found that conditional on the weather at the time of purchase, colder weather in the days leading up to the purchase did not lead to increased sales relative to warmer weather in the days leading up to the purchase for convertibles. While this finding goes against the prediction the salience model would make if the previous days' weather is what the choice context expectation is based on, it is also possible that buying a car a few days earlier is not in a consumers' choice context (or maybe it is only a small part of the overall choice context that consumers use, making this effect hard to identify). Overall, it is very difficult to distinguish between projection bias and salience in this domain and our primary results are consistent with either model.

\section{Conclusion}

Many of the most important decisions that we make in life are decisions with long-term implications. Our ability to make these decisions well depends in part on our ability to forecast accurately our intertemporal utility. In this paper, we have examined purchasing behavior in the car market and found evidence that consumers are affected by projection bias or salience, limiting their ability to make the decision that will maximize their long-term utility. We argue that our results imply that behavioral biases can have important implications for large-stakes markets and that these biases merit additional study and attention.

From a policy perspective, our results suggest that consumers would benefit from laws designed to help them better evaluate their decisions. For example, laws that allow consumers a "cooling-off

\footnotetext{
${ }^{24}$ This prediction of a model of salience provides the same prediction as intertemporal substitution of car purchases.
} 
period" for durable goods or goods for which consumers sign extended contracts may provide significant benefits to consumers (Lowenstein, O’Donoghue, and Rabin, 2003). Such laws could also provide incentives for sellers to help buyers be in a "cool" state before an important transaction or contract is made. ${ }^{25}$ The Federal Trade Commission has an explicit "Cooling-Off Rule" that applies to situations when "[you] buy an item in your home or at a location that is not the seller's permanent place of business." ${ }^{26}$ This rule was made specifically to deal with high-pressure sale situations such as door-to-door sales. The Federal Trade Commission's cooling-off rule does not apply to automobile sales even though there clearly can be high-pressure sale situations for this important durable good. While our results suggest that some consumers might benefit from an opportunity to reverse a decision once they have "cooled-off," applying a cooling-off rule to vehicle purchases would provide other consumers an opportunity to game the system by "buying" a new convertible at the beginning of a holiday weekend and returning it after a few days, claiming to have had a change of heart.

Despite showing that intertemporal behavioral biases can impact an important consumer durable good market, there are many questions about the behavioral bias we have documented that are left unanswered and that future research may be able to address. For example, it is unclear how easy it is to "de-bias" consumers. It is possible that simply providing consumers with information about how intertemporal choices can be influenced by behavioral biases, or asking them to imagine how they will feel about their purchase in a different state of the world, could lead to improved decision making. Another extension of our research that would be particularly useful would be to study behavioral biases in intertemporal choice in various other important empirical contexts such as the decision of a couple to have a baby, whether to get married, which house to buy, or whether to accept a given job offer. Studying intertemporal choice bias in other important settings such as these, may offer additional empirical tests that could shed light on the relative strength and

\footnotetext{
${ }^{25}$ See Camerer et al. (2003) for an extended discussion about cooling-off periods and their potential applications in settings where people make suboptimal choices.

${ }^{26}$ More information on the Federal Trade Commission's "Cooling-Off Rule" can be found on their webpage at: http://www.ftc.gov/bcp/edu/pubs/consumer/products/pro03.shtm .
} 
importance of the underlying behavioral mechanisms (i.e. projection bias and salience) that have been hypothesized in the literature in these different choice contexts. 


\section{References}

Berry, S., J. Levinsohn, and A. Pakes. 1995. “Automobile Prices in Market Equilibrium.” Econometrica, 63(4): 841-890.

Bordalo, Pedro, Nicola Gennaioli, and Andrei Shleifer. 2012a. "Salience Theory of Choice Under Risk," Quarterly Journal of Economics, 127(3), 1243-1285.

Bordalo, Pedro, Nicola Gennaioli, and Andrei Shleifer. 2012b. "Salience and Consumer Choice," NBER Working Paper \#w17947.

Busse, M. 2012. "When Supply and Demand Just Won't Do: Using the Equillibrium Locus to Think about Comparative Statics.” Mimeo, Northwestern University.

Busse, M., C. Knittel, and F. Zettelmeyer. 2013. "Are Consumers Myopic?: Evidence from New and Used Car Purchases.” American Economic Review, 103(1): 220-256.

Busse, M., D. Simester, and F. Zettelmeyer. 2010. “ 'The Best Price You'll Ever Get': The 2005 Employee Discount Pricing Promotions in The U.S. Automobile Industry." Marketing Science, 29(2): 268-290.

Camerer, C., S. Issacharoff, G. Loewenstein, T. O’Donoghue, and M. Rabin. 2003. "Regulation for Conservatives: Behavioral Economics and the Case for "Asymmetric Paternalism"' University of Pennsylvania Law Review, 151(3): 1211-1254.

Conlin, M., T. O’Donoghue, and T. Vogelsang. 2007. "Projection Bias in Catalog Orders." American Economic Review, 97(4): 1217-1249.

Deschenes, O. and E. Moretti. 2009. "Extreme Weather Events, Mortality, and Migration.” Review of Economics and Statistics, 91(4), 659-681.

DellaVigna, S. 2009. "Psychology and Economics: Evidence from the Field." Journal of Economic Literature, 47, 315-372.

Hastings, J. and J. Shapiro. 2012. "Mental Accounting and Consumer Choice: Evidence from Commodity Price Shocks.” NBER Working Paper \#18248.

Hirshleifer, David and Tyler Shumway. 2003. "Good Day Sunshine: Stock Returns and the Weather," Journal of Finance, 58, 1009-1032.

Jacob, B., L. Lefgren, and E. Moretti. 2007. "The Dynamics of Criminal Behavior: Evidence from Weather Shocks." The Journal of Human Resources, 42(3), 489-527.

Koszegi, Botond, and Adam Szeidl. 2013. "A Model of Focusing in Economic Choice," Quarterly Journal of Economics, 128(1), 53-107.

Laibson, D. 1997. "Golden Eggs and Hyperbolic Discounting.” Quarterly Journal of Economics, 112(2), 
443-77.

Levitt, S. and C. Syverson. 2008. "Market Distortions When Agents Are Better Informed: The Value of Information in Real Estate Transactions." The Review of Economics and Statistics, 90(4), 599611.

Li, Y., E. Johnson, and L. Zaval. 2011. "Local Warming: Daily Temperature Change Influences Belief in Global Warming." Psychological Science, 22(4), 454-459.

Loewenstein, G. 1996. “Out of Control: Visceral Influences on Behavior.” Organizational Behavior and Human Decision Processes, 65, 272-292.

Loewenstein, G., D. Nagin, and R. Paternoster. 1997. “The Effect of Sexual Arousal on Predictions of Sexual Forcefulness." Journal of Crime and Delinquency, 32, 443-473.

Loewenstein, G., T. O’Donoghue, and M. Rabin. 2003. "Projection Bias in Predicting Future Utility." Quarterly Journal of Economics, 118: 1209-1248.

Loewenstein, G. and D. Schkade. 1999. “Wouldn't It Be Nice? Predicting Future Feelings.” in WellBeing: The Foundations of Hedonic Psychology, ed. Daniel Kahneman, Edward Diener, and Norbert Schwarz, 85-105. New York: Russell Sage Foundation.

Nisbett, R. and D. Kanouse. 1968. “Obesity, Hunger, and Supermarket Shopping Behavior.” Paper presented at the 76th Annual Convention of the American Psychological Association, San Francisco, CA.

Nordgren, L., J. Van Der Plight, and F. Van Harreveld. 2006. "Visceral Drives in Retrospect: Explanations About the Inaccessible Past.” Psychological Science, 17, 635-640.

Nordgren, L., J. Van Der Plight, and F. Van Harreveld. 2007. "Evaluating Eve: Visceral States Influence the Evaluation of Impulsive Behavior." Journal of Personality and Social Psychology, 93(1), 75-84.

O’Donoghue, T. and M. Rabin. 1999. "Doing It Now or Later." American Economic Review, 89(1): 103-24.

Polk. 2010. "Consumers Continuing to Hold onto Vehicles Longer.” November 3, 2010. https://www.polk.com/company/news/consumers_continuing_to_hold_onto_vehicles_longe r_according_to_polk

Read, D., and B. van Leeuwen. 1998. "Predicting Hunger: The Effects of Appetite and Delay on Choice." Organizational Behavioral and Human Decision Processes, 76, 189-2005.

Risen, J. and C. Critcher. 2011. "Visceral Fit: While in a Visceral State, Associated States of the World Seem More Likely." Journal of Personality and Social Psychology, 100(5), 777-793.

Saunders, Edward M., 1993. "Stock Prices and Wall Street Weather," American Economics Review, 83, 1337-1345. 
Simonsohn, U. 2010. “Weather to Go to College.” Economic Journal, 120(543), 270-280.

Van Boven, L. and G. Loewenstein. 2003. "Social Projection of Transient Drive States.” Personality and Social Psychology Bulletin, 29, 1159-1168.

Zettelmeyer, F., F. Scott Morton, J. Silva-Risso. 2007. "Scarcity Rents in Car Retailing: Evidence from Inventory Fluctuations at Dealerships.” Mimeo, Northwestern University. 
Figure 1. Flexible Relationship Between Temperature and Convertible Purchases. This figure provides the coefficient values and $95 \%$ confidence intervals for the effect of daily high temperature on the probability of purchasing a convertible. Each dot plots the coefficient from the exact same

regression reported in Column 1 of Table 2, but with dummy variables for 5-degree bins of temperature used in place of the linear temperature term. The omitted temperature category is less than 25 degrees.

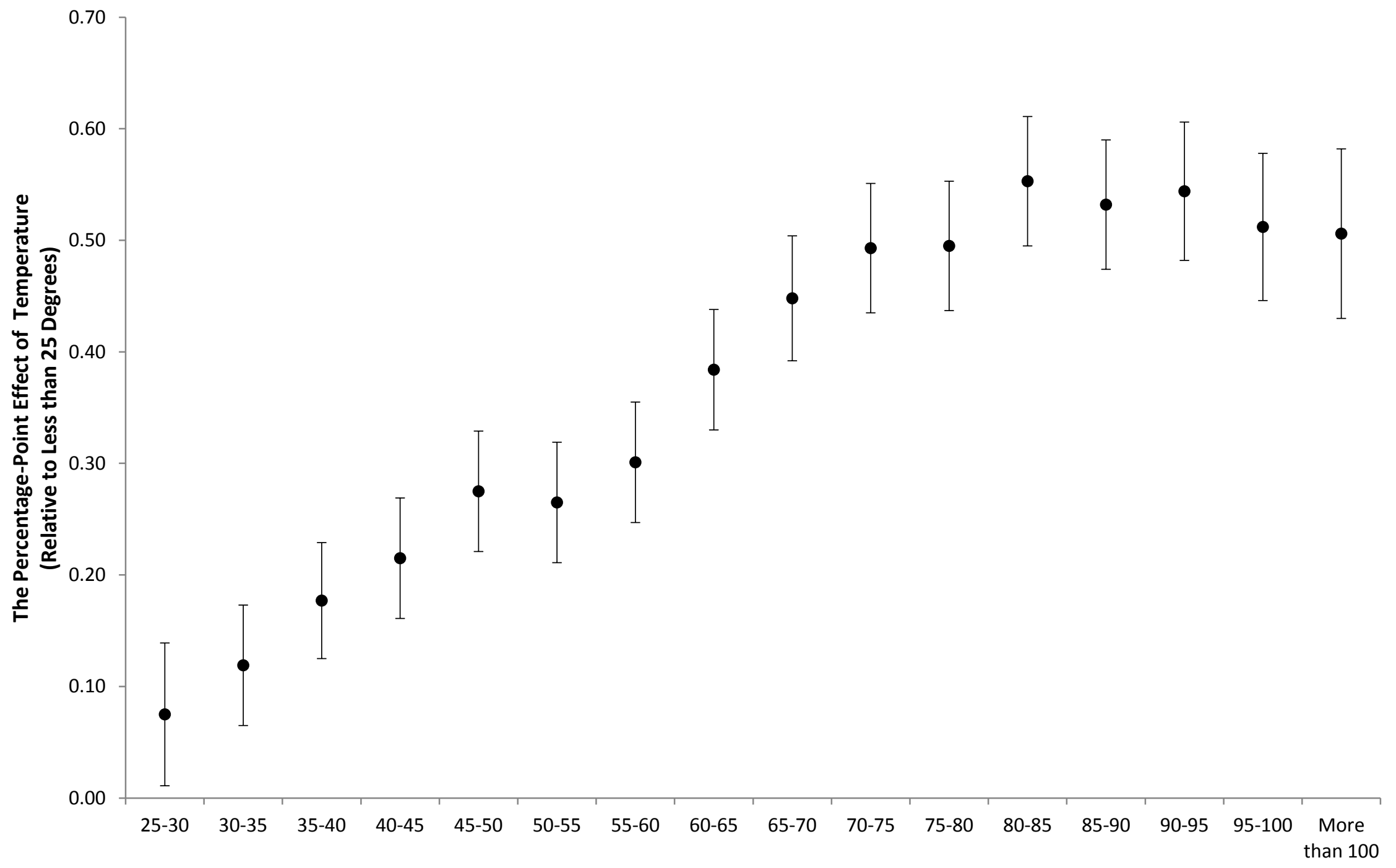

High Temperature Value (Degrees Fahrenheit) 
Figure 2. Flexible Relationship Between Temperature and 4-Wheel-Drive Purchases. This figure provides the coefficient values and $95 \%$ confidence intervals for the effect of daily high temperature on the probability of purchasing a 4-wheel-drive vehicle. Each dot plots the coefficient from the exact same regression reported in Column 1 of Table 3, but with dummy variables for 5-degree bins of temperature used in place of the linear temperature term. The omitted temperature category is less than 25 degrees.

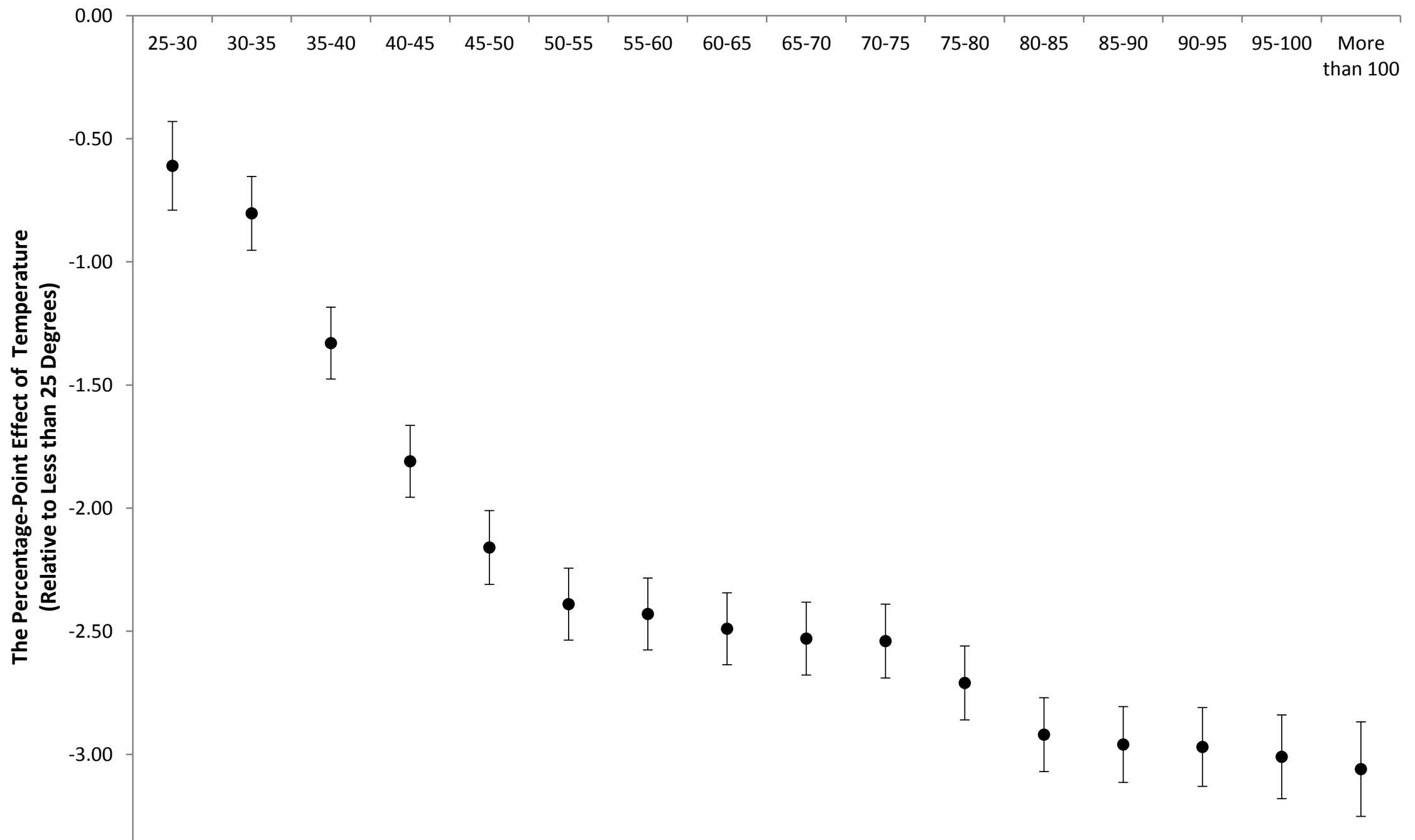

High Temperature Value (Degrees Fahrenheit) 
Figure 3. Dynamic Analysis of Temperature and Convertible Purchases. This figure provides the coefficient values and $95 \%$ confidence intervals for the effect of daily high temperature on the probability of purchasing a convertible. Each dot plots the coefficient of a lag temperature variable from the same regression as reported in Column 1 of Table 2, but with the addition of 60 daily lags of each of the weather variables.

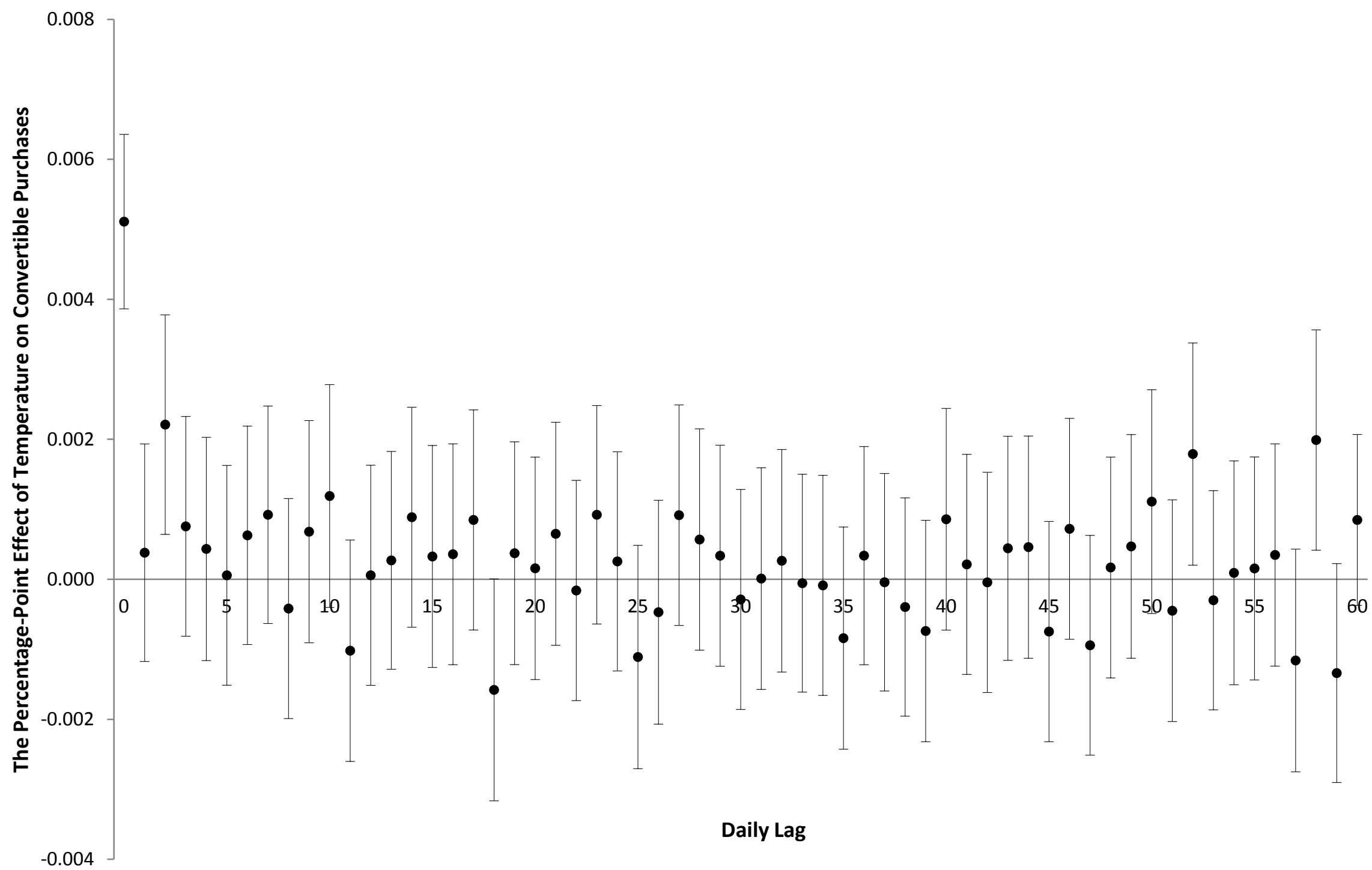


Figure 4. Dynamic Analysis of Cloud Cover and Convertible Purchases. This figure provides the coefficient values and $95 \%$ confidence intervals for the effect of cloud cover (fraction of the sky) on the probability of purchasing a convertible. Each dot plots the coefficient of a lag cloud cover variable from the same regression as reported in Column 1 of Table 2, but with the addition of 60 daily lags of each of the weather variables.

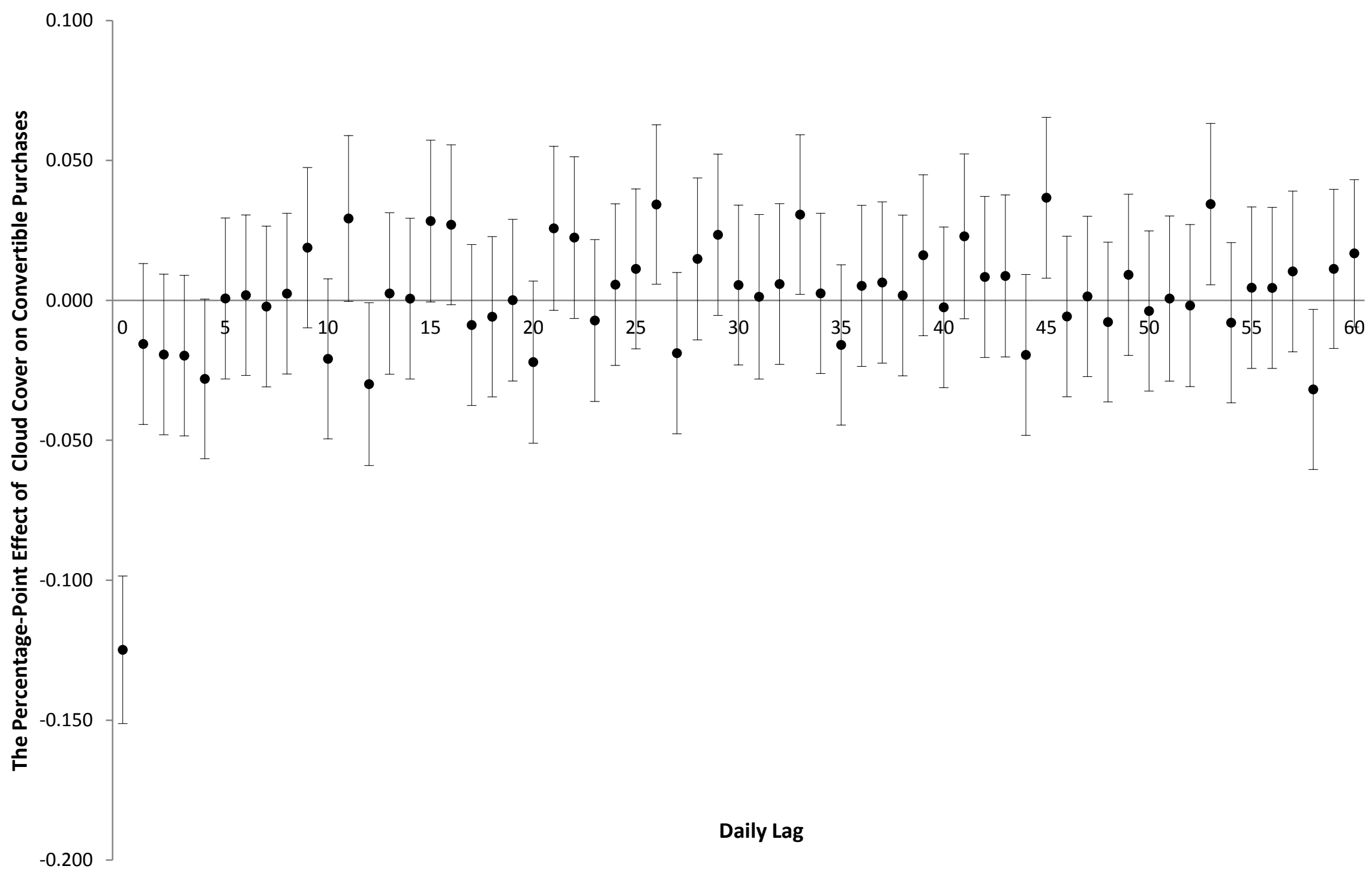


Figure 5. Dynamic Analysis of Temperature and 4WD Purchases. This figure provides the coefficient values and 95\% confidence intervals for the effect of daily high temperature on the probability of purchasing a four-wheel-drive vehicle. Each dot plots the coefficient of a lag temperature variable from the same regression as reported in Column 1 of Table 3, but with the addition of 60 daily lags of each of the weather variables.

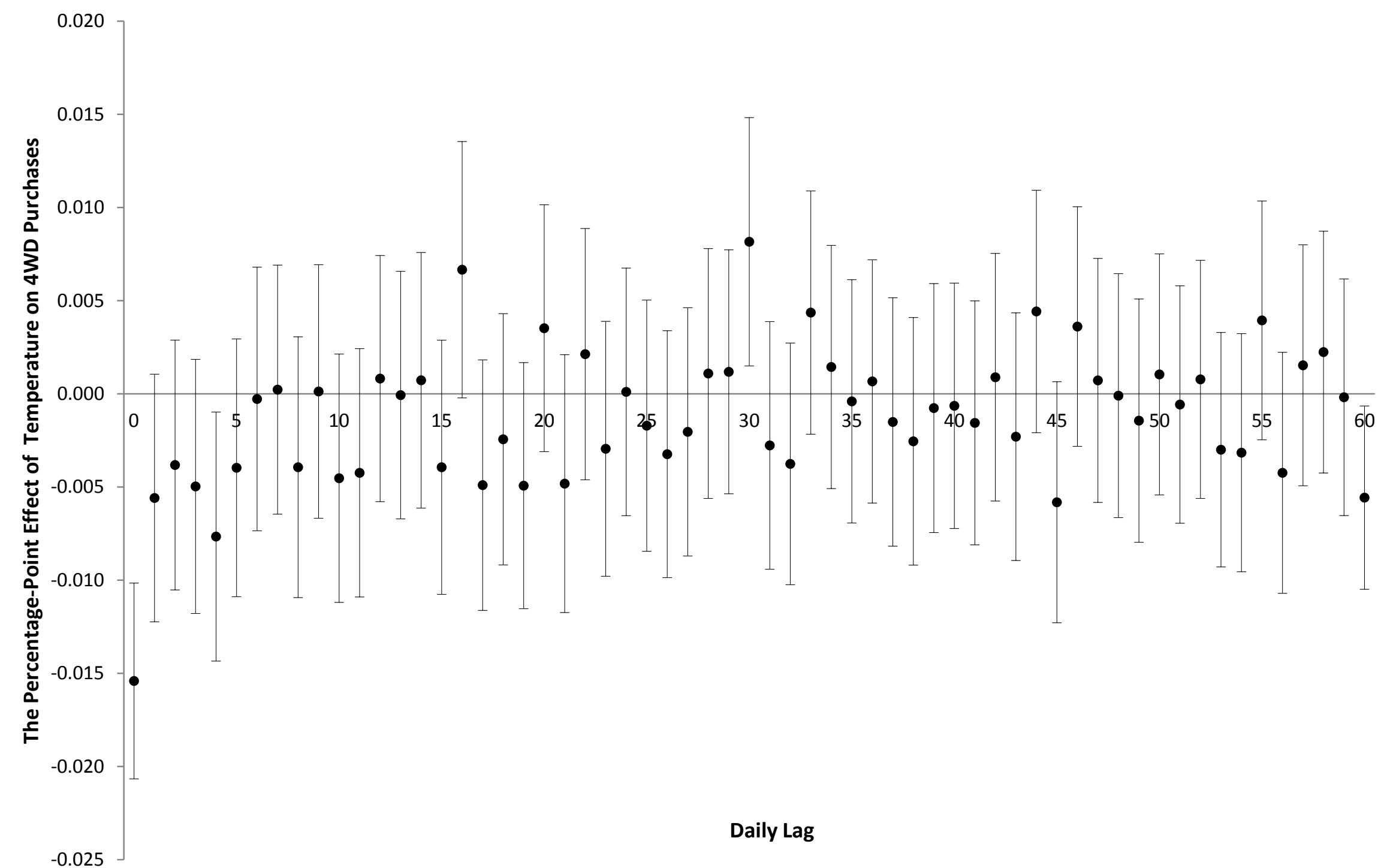


Figure 6. Dynamic Analysis of Snowfall and 4WD Purchases. This figure provides the coefficient values and $95 \%$ confidence intervals for the effect of daily snowfall on the probability of purchasing a four-wheel-drive vehicle. Each dot plots the coefficient of a lag snowfall variable from the same regression as reported in Column 1 of Table 3, but with the addition of 60 daily lags of each of the weather variables.

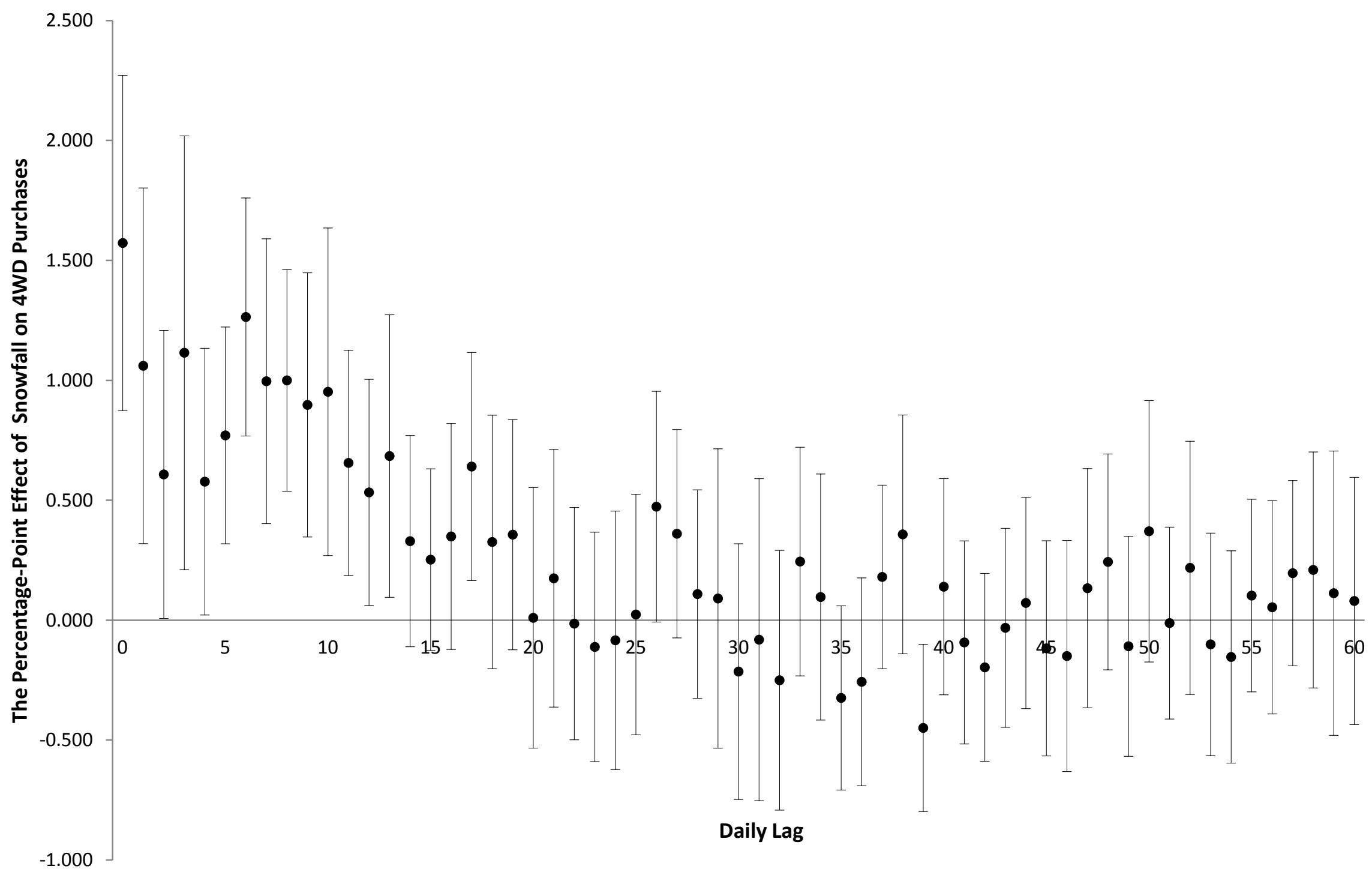


Table 1. Summary Statistics for Retail Vehicle Sales

\begin{tabular}{lcccc}
\hline \hline & Mean & St. Dev. & Min. & Max. \\
\cline { 2 - 5 } Vehicle Characteristics & & & & \\
Convertible Indicator & .022 & 0.145 & 0 & 1 \\
4-Wheel Drive Indicator & .267 & 0.442 & 0 & \\
Weather Variables & & & & 120.9 \\
Max Temperature & 71.4 & 17.8 & -38.9 & 33.9 \\
Rain Fall & 0.202 & 0.758 & 0 & 8.53 \\
Snow Fall & 0.004 & 0.058 & 0 & 22.0 \\
Slush Fall & 0.011 & 0.148 & 0 & 1 \\
Cloud Cover & 0.526 & 0.322 & 0 & $40,164,136$ \\
Observations & $40,164,136$ & $40,164,136$ & $40,164,136$ &
\end{tabular}

Notes: Summary statistics are reported for all vehicle sales in our dataset between 2001 and 2008 . 
Table 2. Effect of Weather on Convertible Purchases

\begin{tabular}{|c|c|c|c|c|c|}
\hline & \multicolumn{5}{|c|}{ Dependent Variable: Indicator Equal to 1 if Purchase was a Convertible } \\
\hline \multirow[b]{2}{*}{ Temperature } & Full Year & Quarter 1 & Quarter 2 & Quarter 3 & Quarter 4 \\
\hline & $\begin{array}{l}.007^{\star \star} \\
(.0004)\end{array}$ & $\begin{array}{l}.010^{\star \star} \\
(.001)\end{array}$ & $\begin{array}{l}.008^{\star \star} \\
(.001)\end{array}$ & $\begin{array}{l}.002^{*} \\
(.001)\end{array}$ & $\begin{array}{l}.005^{\star \star} \\
(.001)\end{array}$ \\
\hline Rain Fall & $\begin{array}{c}-.016^{\star \star} \\
(.004)\end{array}$ & $\begin{array}{c}-.035^{\star \star} \\
(.010)\end{array}$ & $\begin{array}{l}-.010 \\
(.007)\end{array}$ & $\begin{array}{c}-.014^{\star \star} \\
(.006)\end{array}$ & $\begin{array}{c}-.016^{\star *} \\
(.007)\end{array}$ \\
\hline Snow Fall & $\begin{array}{l}-.053 \\
(.036)\end{array}$ & $\begin{array}{l}-.021 \\
(.053)\end{array}$ & $\begin{array}{l}-.193 \\
(.126)\end{array}$ & $\begin{array}{l}-8.178 \\
(8.517)\end{array}$ & $\begin{array}{l}-.047 \\
(.048)\end{array}$ \\
\hline Slush Fall & $\begin{array}{c}-.043^{* *} \\
(.015)\end{array}$ & $\begin{array}{l}-.036 \\
(.021)\end{array}$ & $\begin{array}{l}-.067^{*} \\
(.033)\end{array}$ & $\begin{array}{c}.019 \\
(.033)\end{array}$ & $\begin{array}{l}-.058^{*} \\
(.027)\end{array}$ \\
\hline Cloud Cover & $\begin{array}{l}-.126^{\star \star} \\
(.010)\end{array}$ & $\begin{array}{l}-.114^{\star *} \\
(.018)\end{array}$ & $\begin{array}{l}-.206^{\star \star} \\
(.022)\end{array}$ & $\begin{array}{l}-.120^{\star *} \\
(.020)\end{array}$ & $\begin{array}{l}-.087^{\star *} \\
(.017)\end{array}$ \\
\hline Year F.E.s & $\mathrm{X}$ & $x$ & $x$ & $\mathrm{x}$ & $\mathrm{x}$ \\
\hline DMA*Week-of-the-Year F.E.s & $\mathrm{X}$ & $X$ & $X$ & $\mathrm{X}$ & $\mathrm{x}$ \\
\hline R-Squared & 0.003 & 0.003 & 0.002 & 0.002 & 0.003 \\
\hline Observations & $39,984,509$ & $9,150,047$ & $10,205,673$ & $10,608,527$ & $10,020,262$ \\
\hline \multicolumn{6}{|c|}{$\begin{array}{l}\text { Notes: Coefficient values and clustered standard errors are presented from OLS regressions of an indicator for whether a car } \\
\text { sold was a convertible on weather variables - temperature (degrees Fahrenheit), rain (inches), snow (liquidized inches), slush } \\
\text { (liquidized inches), and cloud cover (fraction of sky covered). Fixed effects are included for each year and for DMA*Week-of-the- } \\
\text { Year (Week } 1-\text { Week } 52 \text { ). The first column uses all the data while the next four columns present results separately for the four } \\
\text { quarters of the year. All coefficients and standard errors have been multiplied by } 100 \text { for ease of presentation. Thus each } \\
\text { coefficient represents the percentage point change in probability of purchasing a covertible. Standard errors are clustered at the } \\
\text { DMA*day. } \\
{ }^{*} \text { significant at } 5 \% ;{ }^{* *} \text { significant at } 1 \%\end{array}$} \\
\hline
\end{tabular}


Table 3. Effect of Weather on 4-Wheel-Drive Purchases

\begin{tabular}{|c|c|c|c|c|c|}
\hline & \multicolumn{5}{|c|}{ Dependent Variable: Indicator Equal to 1 if Purchase was a 4WD } \\
\hline & Full Year & Quarter 1 & Quarter 2 & Quarter 3 & Quarter 4 \\
\hline Temperature & $\begin{array}{l}.032^{* *} \\
(.001)\end{array}$ & $\begin{array}{c}.038^{* *} \\
(.002)\end{array}$ & $\begin{array}{l}.018^{* *} \\
(.003)\end{array}$ & $\begin{array}{l}-.029^{\star *} \\
(.004)\end{array}$ & $\begin{array}{c}.038^{\star *} \\
(.003)\end{array}$ \\
\hline Rain Fall & $\begin{array}{l}.084^{* *} \\
(.014)\end{array}$ & $\begin{array}{l}.119^{* *} \\
(.036)\end{array}$ & $\begin{array}{l}.081^{* *} \\
(.026)\end{array}$ & $\begin{array}{l}.054^{* *} \\
(.023)\end{array}$ & $\begin{array}{l}.132^{\star *} \\
(.032)\end{array}$ \\
\hline Snow Fall & $\begin{array}{l}1.81^{* *} \\
(.26)\end{array}$ & $\begin{array}{c}1.67^{* *} \\
(.33)\end{array}$ & $\begin{array}{c}.72 \\
(.82)\end{array}$ & $\begin{array}{l}125^{*} \\
(53)\end{array}$ & $\begin{array}{c}2.11^{* *} \\
(.48)\end{array}$ \\
\hline Slush Fall & $\begin{array}{l}.504^{\star *} \\
(.077)\end{array}$ & $\begin{array}{l}.540^{\star *} \\
(.110)\end{array}$ & $\begin{array}{c}.27 \\
(.22)\end{array}$ & $\begin{array}{l}-.029 \\
(.167)\end{array}$ & $\begin{array}{l}.769^{\star *} \\
(.166)\end{array}$ \\
\hline Cloud Cover & $\begin{array}{l}.461^{* *} \\
(.039)\end{array}$ & $\begin{array}{l}.337^{* *} \\
(.072)\end{array}$ & $\begin{array}{l}.512^{* *} \\
(.077)\end{array}$ & $\begin{array}{l}.383^{\star *} \\
(.087)\end{array}$ & $\begin{array}{l}.598^{* *} \\
(.076)\end{array}$ \\
\hline Year F.E.s & $x$ & $x$ & $x$ & $x$ & $x$ \\
\hline DMA*Week-of-the-Year F.E.s & $x$ & $x$ & $x$ & $x$ & $x$ \\
\hline R-Squared & 0.086 & 0.086 & 0.074 & 0.084 & 0.097 \\
\hline Observations & $39,984,509$ & $9,150,047$ & $10,205,673$ & $10,608,527$ & $10,020,262$ \\
\hline
\end{tabular}

Notes: Coefficient values and clustered standard errors are presented from OLS regressions of an indicator for whether a car sold was a 4-wheel drive on weather variables - temperature (degrees Fahrenheit), rain (inches), snow (liquidized inches), slush (liquidized inches), and cloud cover (fraction of sky covered). Fixed effects are included for each year and for DMA*Week-of-theYear (Week 1 - Week 52). The first column uses all the data while the next four columns present results separately for the four quarters of the year. All coefficients and standard errors have been multiplied by 100 for ease of presentation. Thus each coefficient represents the percentage point change in probability of purchasing a covertible. Standard errors are clustered at the $\mathrm{DMA}^{*}$ day.

${ }^{*}$ significant at $5 \% ;{ }^{* *}$ significant at $1 \%$ 
Table 4. Effect of Weather on Convertible and 4-Wheel Drive Purchase Price

\begin{tabular}{|c|c|c|c|c|}
\hline & \multicolumn{4}{|c|}{ Dependent Variable: Vehicle Sales Price (Less Rebate) } \\
\hline & \multicolumn{2}{|c|}{ Convertibles } & \multicolumn{2}{|c|}{ 4-Wheel Drives } \\
\hline & New & Used & New & Used \\
\hline Mean of Dependent Variable & $\$ 40,001$ & $\$ 22,222$ & $\$ 31,845$ & $\$ 19,132$ \\
\hline Temperature & $\begin{array}{c}0.91 \\
(0.89)\end{array}$ & $\begin{array}{r}0.74 \\
(0.92)\end{array}$ & $\begin{array}{c}0.23 \\
(0.25)\end{array}$ & $\begin{array}{l}0.27 \\
(.18)\end{array}$ \\
\hline Rain Fall & $\begin{array}{l}-3.15 \\
(8.77)\end{array}$ & $\begin{array}{l}-11.25 \\
(9.61)\end{array}$ & $\begin{array}{c}1.55 \\
(2.93)\end{array}$ & $\begin{array}{l}6.95^{\star *} \\
(2.17)\end{array}$ \\
\hline Snow Fall & $\begin{array}{c}156.74 \\
(128.05)\end{array}$ & $\begin{array}{c}86.41 \\
(138.33)\end{array}$ & $\begin{array}{c}11.69 \\
(28.43)\end{array}$ & $\begin{array}{l}-13.82 \\
(19.56)\end{array}$ \\
\hline Slush Fall & $\begin{array}{l}-41.66 \\
(48.32)\end{array}$ & $\begin{array}{c}1.06 \\
(47.42)\end{array}$ & $\begin{array}{c}-1.39 \\
(12.21)\end{array}$ & $\begin{array}{l}-4.33 \\
(8.22)\end{array}$ \\
\hline Cloud Cover & $\begin{array}{c}4.95 \\
(24.04)\end{array}$ & $\begin{array}{l}-31.24 \\
(25.39)\end{array}$ & $\begin{array}{c}21.69^{* *} \\
(7.34)\end{array}$ & $\begin{array}{c}-23.79^{* *} \\
(5.25)\end{array}$ \\
\hline Year F.E.s & $\mathrm{X}$ & $\mathrm{X}$ & $\mathrm{X}$ & $\mathrm{x}$ \\
\hline DMA*Week-of-the-Year F.E.s & $\mathrm{X}$ & $\mathrm{X}$ & $\mathrm{X}$ & $\mathrm{x}$ \\
\hline Purchase Timing F.E.s & $\mathrm{X}$ & $\mathrm{X}$ & $x$ & $x$ \\
\hline Vehicle-type F.E.s & $\mathrm{X}$ & $x$ & $X$ & $x$ \\
\hline Odometer Value Spline & & $\mathrm{x}$ & & $x$ \\
\hline Observations & 385,771 & 371,790 & $5,405,663$ & $4,076,024$ \\
\hline
\end{tabular}

Notes: Coefficient values and standard errors are presented from OLS regressions of vehicle transaction prices on weather variables - temperature (degrees Fahrenheit), rain (inches), snow (liquidized inches), slush (liquidized inches), and cloud cover (fraction of sky covered). Each observation is an individual transaction. Fixed effects are included for Year and for DMA*Week-of-the-Year (Week 1 - Week 52), and for detailed vehicle types. Purchase Timing indicates whether a vehicle was purchased on a weekend or at the end of the month. The first two columns present results for new and used convertibles, respectively, while the second two columns present results for new and used 4-wheel drives. The used vehicle specifications (columns 2 and 4) include a linear spline in odometer values with knots at 10,000 mile increments.

${ }^{*}$ significant at $5 \% ;{ }^{* *}$ significant at $1 \%$ 
Table 5. Effect of Weather on Convertible and 4-Wheel Drive Purchases for Consumers Trading in a Convertible or 4-Wheel Drive Vehicle, Respectively

\begin{tabular}{lcc}
\hline \hline & \multicolumn{2}{c}{ Dep. Var.: Indicator Equal to 1 if Purchase was a } \\
& Convertible/4WD & 4-Wheel Drives \\
\cline { 2 - 3 } Temperature & Convertibles & $-.043^{* *}$ \\
\cline { 2 - 3 } Rain Fall & $.065^{\star *}$ & $(.003)$ \\
& $(.011)$ & $.129^{* *}$ \\
Snow Fall & -.196 & $(.039)$ \\
& $(.102)$ & $1.07^{* *}$ \\
Slush Fall & -2.38 & $(.40)$ \\
& $(1.48)$ & $.501^{* *}$ \\
Cloud Cover & -.760 & $(.143)$ \\
& $(.544)$ & $.701^{* *}$ \\
Year F.E.s & -.284 & $(.099)$ \\
DMA*Week-of-the-Year F.E.s & $(.294)$ & $X$ \\
R-Squared & $X$ & $X$ \\
Observations & $X$ & 0.076 \\
\hline
\end{tabular}

Notes: Coefficient values and standard errors are presented from OLS regressions of an indicator for whether a car was a convertible (Column 1) or a 4-wheel drive (Column 2) on weather variables temperature (degrees Fahrenheit), rain (inches), snow (liquidized inches), slush (liquidized inches), and cloud cover (fraction of sky covered). Fixed effects are included for Year and for DMA*Week-ofthe-Year (Week 1 - Week 52). The sample is restricted to people who were purchasing a vehicle while trading in a convertible (Column 1) or a 4-wheel drive (Column 2). Standard errors are clustered at the $\mathrm{DMA}^{*}$ day.

${ }^{*}$ significant at $5 \% ;{ }^{* *}$ significant at $1 \%$ 


\section{Table 6. Effect of Weather on Quickly Trading In a Vehicle}

\begin{tabular}{|c|c|c|c|}
\hline & \multicolumn{3}{|c|}{ Dep. Var.: Dummy Variable if Returned Within 1-3 Years } \\
\hline & 1 Year & 2 Years & 3 Years \\
\hline Percent of Cars Returned in Window & $2.37 \%$ & $5.03 \%$ & $7.16 \%$ \\
\hline Convertible & $\begin{array}{c}1.272^{* *} \\
(.019)\end{array}$ & $\begin{array}{c}2.302^{* *} \\
(.030)\end{array}$ & $\begin{array}{c}2.905^{\star *} \\
(.042)\end{array}$ \\
\hline $\begin{array}{l}\text { Convertible Interacted with: } \\
\text { Temperature }\end{array}$ & $\begin{array}{l}.006 \\
(.004)\end{array}$ & $\begin{array}{l}.017^{\star *} \\
(.007)\end{array}$ & $\begin{array}{l}.006 \\
(.009)\end{array}$ \\
\hline Rain Fall & $\begin{array}{c}.008 \\
(.009)\end{array}$ & $\begin{array}{c}.002 \\
(.015)\end{array}$ & $\begin{array}{l}-.018 \\
(.021)\end{array}$ \\
\hline Snow Fall & $\begin{array}{c}.181 \\
(.131)\end{array}$ & $\begin{array}{l}-.041 \\
(.222)\end{array}$ & $\begin{array}{l}-.142 \\
(.289)\end{array}$ \\
\hline Slush Fall & $\begin{array}{l}.063 \\
(.053)\end{array}$ & $\begin{array}{l}.028 \\
(.094)\end{array}$ & $\begin{array}{l}-.116 \\
(.131)\end{array}$ \\
\hline Cloud Cover & $\begin{array}{l}-.197 \\
(.138)\end{array}$ & $\begin{array}{l}-.036 \\
(.228)\end{array}$ & $\begin{array}{c}.332 \\
(.312)\end{array}$ \\
\hline 4-Wheel Drive & $\begin{array}{l}.285^{\star *} \\
(.006)\end{array}$ & $\begin{array}{l}.929^{* *} \\
(.006)\end{array}$ & $\begin{array}{l}1.634^{* *} \\
(.014)\end{array}$ \\
\hline $\begin{array}{l}\text { 4-Wheel Drive Interacted With: } \\
\text { Temperature }\end{array}$ & $\begin{array}{l}-.003^{*} \\
(.001)\end{array}$ & $\begin{array}{l}-.005^{*} \\
(.002)\end{array}$ & $\begin{array}{c}-.013^{* *} \\
(.003)\end{array}$ \\
\hline Rain Fall & $\begin{array}{l}-.005 \\
(.003)\end{array}$ & $\begin{array}{l}-.005 \\
(.006)\end{array}$ & $\begin{array}{c}.001 \\
(.008)\end{array}$ \\
\hline Snow Fall & $\begin{array}{l}.000 \\
(.035)\end{array}$ & $\begin{array}{l}.063 \\
(.058)\end{array}$ & $\begin{array}{l}.004 \\
(.076)\end{array}$ \\
\hline Slush Fall & $\begin{array}{l}.002 \\
(.016)\end{array}$ & $\begin{array}{l}-.019 \\
(.028)\end{array}$ & $\begin{array}{l}-.048 \\
(.038)\end{array}$ \\
\hline Cloud Cover & $\begin{array}{l}.006 \\
(.047)\end{array}$ & $\begin{array}{l}-.109 \\
(.078)\end{array}$ & $\begin{array}{l}-.124 \\
(.106)\end{array}$ \\
\hline DMA*Week Fixed Effects & $\mathrm{X}$ & $\mathrm{X}$ & $\mathrm{X}$ \\
\hline R-Squared & 0.004 & 0.006 & 0.007 \\
\hline Observations & $35,102,062$ & $29,665,047$ & $23,827,418$ \\
\hline
\end{tabular}

Notes: Coefficient values and standard errors are presented from OLS regressions of a dummy variable for whether the transacted vehicle reappears in our dataset (as a trade-in car or as a used-car sale) within 1,2, or 3 years from the date of purchase on a dummy variable for whether the transacted vehicle was a convertible or a 4-wheel drive and an interaction between these dummies and weather variables at the time of purchase - temperature (degrees Fahrenheit), rain (inches), snow (liquidized inches), slush (liquidized inches), and cloud cover (fraction of sky covered). Each observation is at the individual vehicle level and DMA*Week fixed effects are included. The dataset is also restricted so as to eliminate all truncation (Columns 1-3 eliminate the last 1-3 years of car sales in the sample, respectively). All coefficients and standard errors have been multiplied by 100 for ease of presentation.

* significant at $5 \%$; ** significant at $1 \%$ 
Figure A1 - Seasonal Trends in Vehicle Purchases. This figure illustrates the percentage of total vehicles that were sold in each month between 2001 and 2008 that were convertibles (Panel A) and 4-wheel drives (Panel B).

Panel A. Convertible Percentage of Vehicles Sold

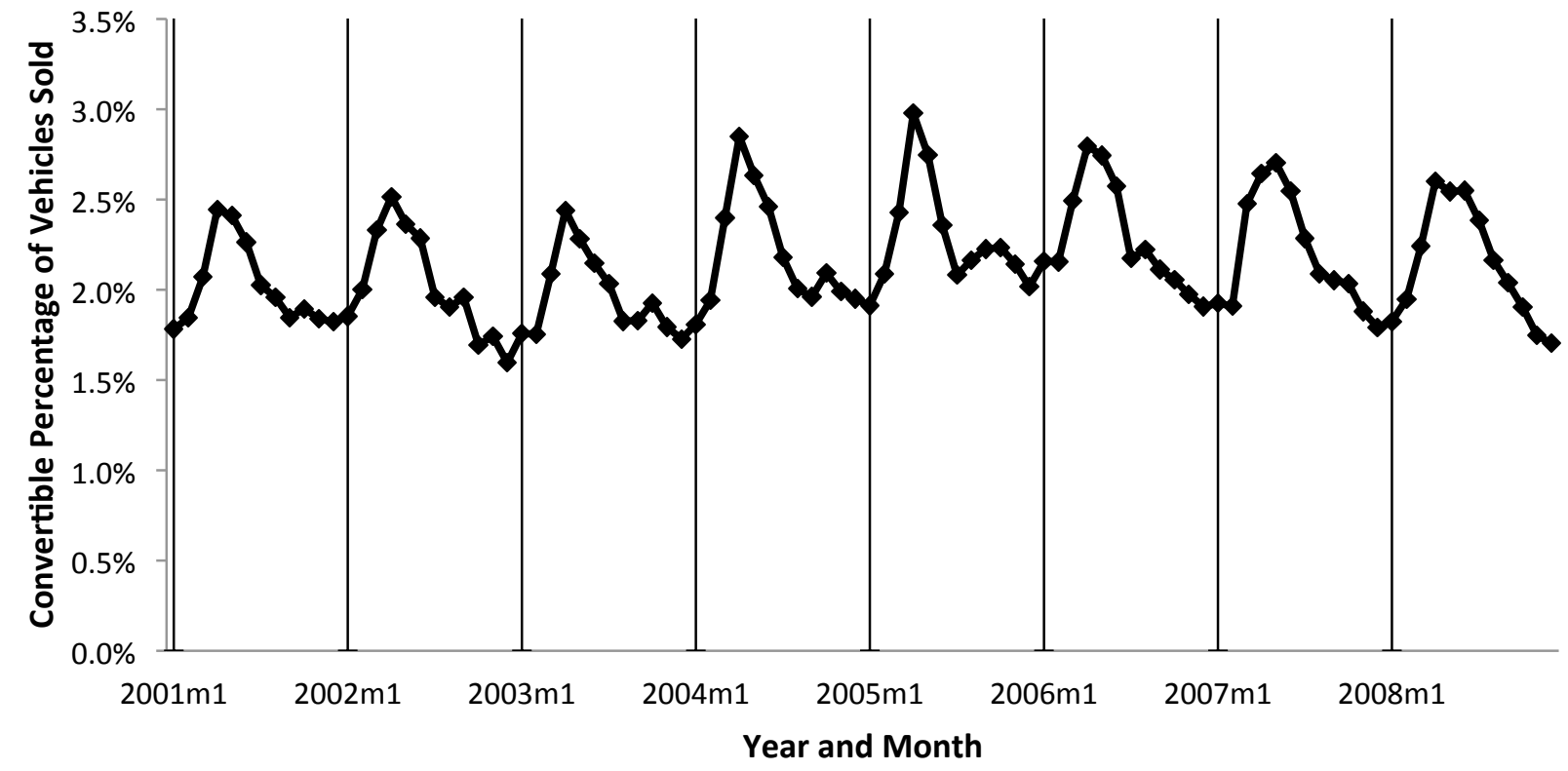

Panel B. 4-Wheel Drive Percentage of Vehicles Sold

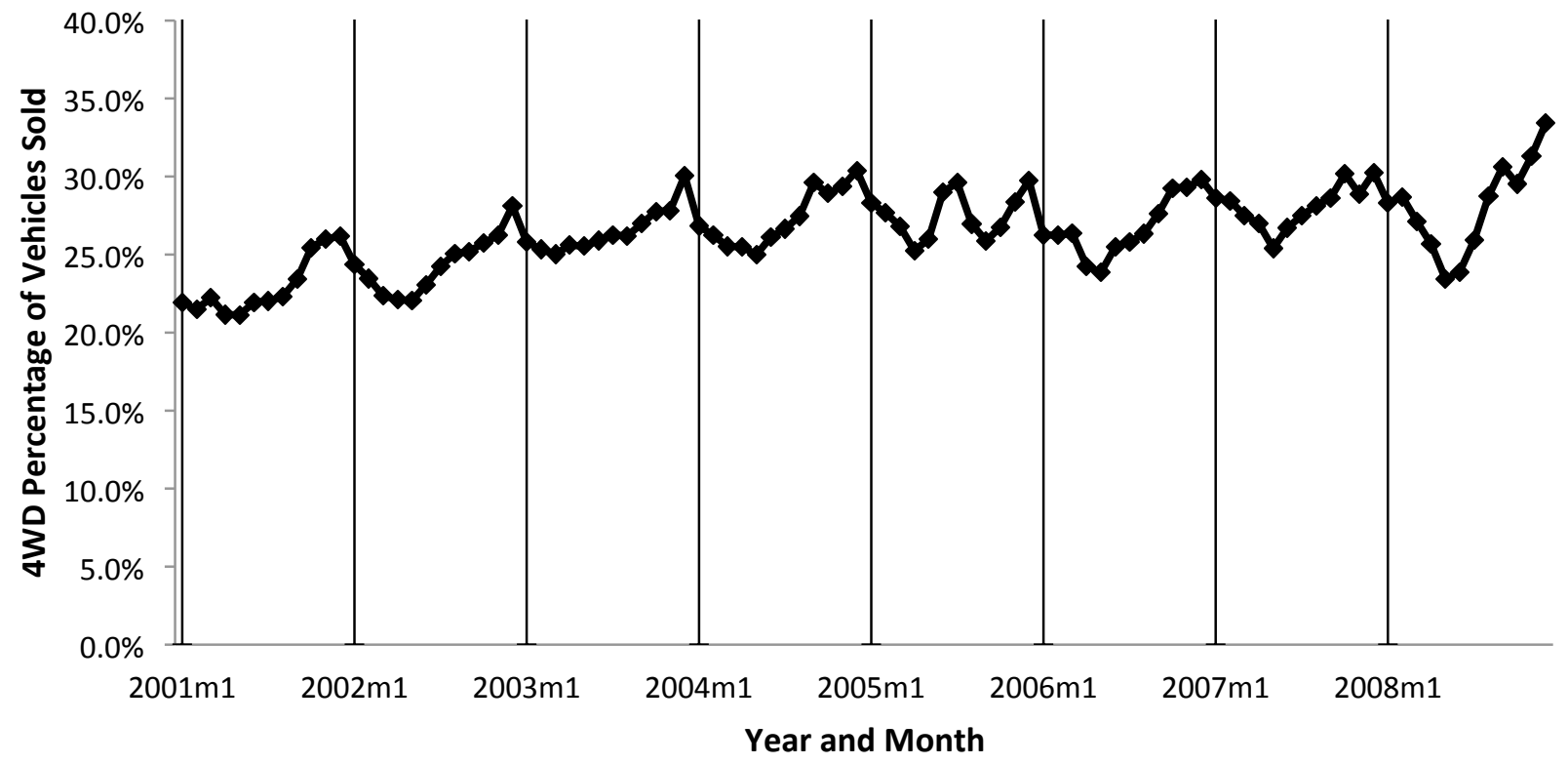


Figure A2 - Seasonal Trends in Vehicle Purchases by Temperature Variation. This figure illustrates the percentage of total vehicles sold between 2001 and 2008 that were convertibles (Panel A) and 4-wheel drives (Panel B) for DMAs with above- and below-median level of monthly DMA temeprature variation.

Panel A. Convertible Percentage of Vehicles Sold by Temperature Variation

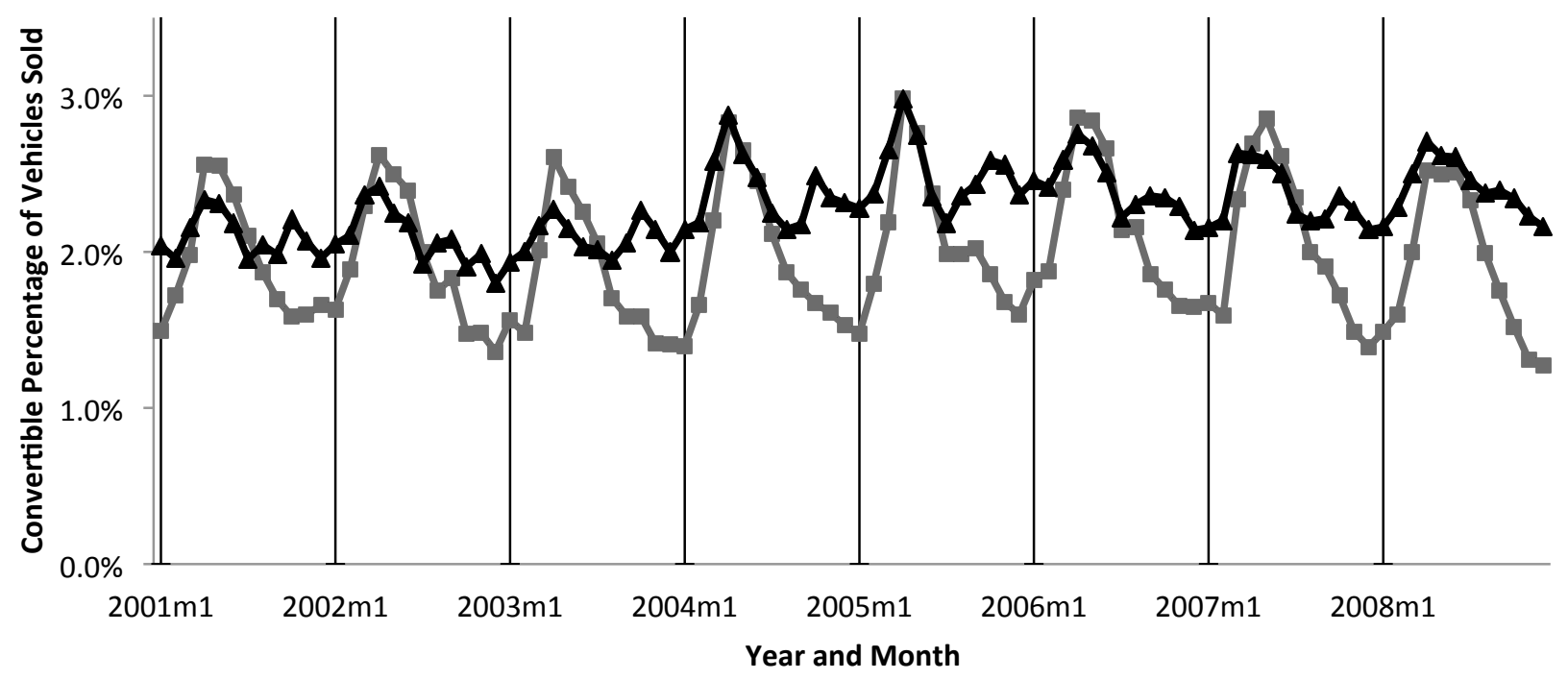

$\rightarrow$ Variable Temperature Area $\quad \longrightarrow$ Non-Variable Temperature Area

Panel B. 4-Wheel Drive Percentage of Vehicles Sold by Temperature Variation

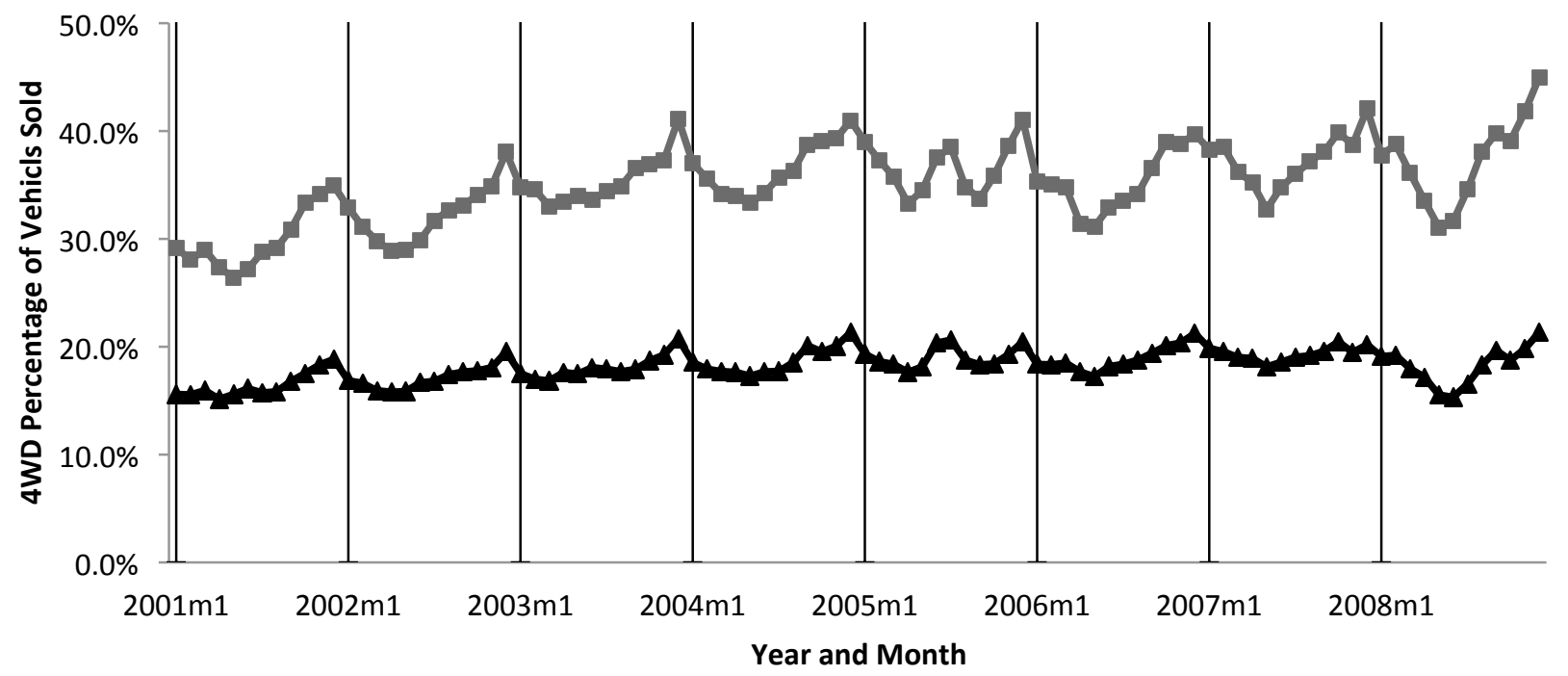

$\rightarrow$ Variable Temperature Area $\quad \rightarrow$ Non-Variable Temperature Area 